Sharif University of Technology
Scientia Iranica
Transactions E: Industrial Engineering
IRA IENTIA $\quad$\begin{tabular}{l} 
h / scientiairanica.sharif.edu \\
\hline
\end{tabular}

\title{
Multi-objective robust mathematical modeling of emergency relief in disaster under uncertainty
}

\author{
A.A. Eshghi ${ }^{a}$, R. Tavakkoli-Moghaddam ${ }^{\text {b*, }}$, S. Ebrahimnejad ${ }^{\text {c }}$, and V.R. Ghezavati ${ }^{\mathrm{a}}$ \\ a. School of Industrial Engineering, South Tehran Branch, Islamic Azad University, Tehran, Iran. \\ b. School of Industrial Engineering, College of Engineering, University of Tehran, Tehran, Iran. \\ c. Department of Industrial Engineering, Karaj Branch, Islamic Azad University, Karaj, Iran.
}

Received 22 September 2019; received in revised form 30 July 2020; accepted 18 October 2020

\section{KEYWORDS}

Location-allocation planning;

Robust optimization;

Emergency relief;

Disaster;

Multi-objective

evolutionary

algorithm.

\begin{abstract}
This paper presents a robust location-allocation planning problem for emergency relief in a disaster situation. It is a multi-objective, multi-commodity, multivehicle, and multi-level logistics model that considers injury variety through service prioritizing for injuries. Furthermore, it incorporates unmet demand for particular item types in various damaged areas. Public donation of different relief goods through capacitated medical centers and emergency centers is also addressed with regard to damage type, capacitated relief distribution centers, and disaster management centers. The model is a non-linear mixed-integer programming that simultaneously optimizes three objectives, namely maximizing service fairness to damaged areas, maximizing fair commodity disaster management, and minimizing the total logistics cost. To solve such a hard problem, a Non-dominated Sorting Genetic Algorithm-II (NSGA-II) was developed and the Taguchi method was employed to adjust its parameters. The $\varepsilon$-constraint method was used for the evaluation of the performance of the proposed algorithm. For more accurate validation, three comparison metrics including diversification, spacing, and mean ideal distance were adopted. The results verified the effectiveness of the algorithm in a reasonable computational time. Eventually, to examine the applicability of the presented model and the proposed algorithm, a case study was analyzed in an area located in the north of Iran, known for historical earthquake records and aggregated active faults.
\end{abstract}

(C) 2022 Sharif University of Technology. All rights reserved.

\section{Introduction}

People are the main asset of a country. The basis and purpose of plans and programs are to provide an environment in which people can live in a desirable quality. Human resource development plays a key role in achieving this target. Some countries have suffered huge damages and experienced the crash of

\footnotetext{
*. Corresponding author.

E-mail address: tavakoli@ut.ac.ir (R.

Tavakkoli-Moghaddam)
}

doi: $10.24200 /$ sci.2020.54485.3770 their productive, economic, and even environmental facilities in recent decades. However, their skilled manpower, proper planning, and proactive preparation of environments that minimize vulnerability to disasters have helped them successfully recover from such damages. On the other hand, there are other countries, some of which possess rather rich resources, that have remained ineffective or even vulnerable due to poor manpower, weak management, and lack of planning.

Today, despite scientific and technological advances, problems due to natural disasters (e.g., earthquakes, floods, storms, lightning, avalanches, tornadoes, fires, and volcanoes) affect various parts of the world, causing heavy casualties and damaging popula- 
tions and assets [1,2]. At the time of such disasters, the demand for rescue and relief operations becomes huge and unpredictable. Rapid response is necessary in treating injuries, delivering relief and medical supplies, and transferring injured people to medical facilities at the right time in order to reduce casualties and help suffering people [3]. Therefore, an appropriate humanitarian logistics system is necessary to tackle problems caused by disasters through prioritizing, planning, organization, guidance, leadership, and control of the vital activities for restoring the normal situation.

As a result, research for planning the disastrous situations has gradually drawn attention in the field of humanitarian logistics. Especially, in highly accidentprone areas, humanitarian logistics is employed as a tool in disastrous situations to make more effective efforts in reducing the casualties. Qureshi and Taniguchi [4] focused on efficient and timely humanitarian logistics to save lives and reduce trauma. They developed a humanitarian logistics model with limited availability of resources, equity of distribution, and availability of residual capacity in the road network and implemented a case study in Osaka, Japan. Effective humanitarian logistics is vitally important also in Turkey given the frequent natural disasters that occur in the country. Gökçe and Ercan [5] investigated locating disaster stations in neighborhoods (i.e., containers filled with necessary items such as medicine, painkillers, and canned goods at specified locations) in Turkey to prevent shortage during disasters.

However, the stochastic and unpredictable nature of disasters, especially earthquakes, which is one of the crises under consideration in this study, requires comprehensive and complete plans to help rescue injured people and respond to their needs afterward. According to the EM-DAT database (International Disaster Database at http://www.emdat.be/database), 25 types of disasters or crises reported have caused more than 50,000 deaths between 1900 and 2011. Of these 25 types of crises, there are 12 earthquakes, 7 tropical storms, and 6 floods. The risk of specific disasters varies considerably from region to region [6].

According to Berke [7], disaster-related casualties in the less developed countries of Asia, Africa, and South America are about 3,000, compared with about 500 deaths in high-income countries. These differences seem to be growing, as the average annual mortality rate in developed countries has dropped by not less than $75 \%$ between 1960 and 1990 . On the other hand, there has been an increase of more than $400 \%$ in this rate in the less developed countries. Also, losses in structure, animals, and products, which are the most important criteria for physical effects, have been increasing exponentially all over the world since 1970 . Nevertheless, the increment rate for the less developed countries is larger.
Regarding the high seismicity of Iran due to its location on an earthquake belt, a large number of cities in the country are in danger of earthquakes. For a clear picture, among 678 cities in Iran, 640 are on the earthquake line of which 24 cities are in the high-risk earthquake zone. There are two main earthquake belts on the Earth, namely the Pacific Ocean and the AlpineHimalayan, and Iran is situated in the middle of the Alpine-Himalayan belt [8]. According to studies conducted on four faults, including the Masha, northern Tehran, and southern and northern Ray in Tehran, their activation can lead to various consequences. In line with this, one of the important issues highlighted in recent years in all societies, including Iran, is dealing with the logistical issue of a crisis or relief. This proves the necessity of conducting applied research on relief logistics when dealing with a disaster in order to minimize the damage caused by it.

The provision of required items and their delivery to the affected areas is one of the major challenges of crisis logistics. To ensure that goods can be transferred in the shortest time possible in the event of a disaster, it is possible to optimize the location, determine the optimum capacity of distribution centers in the preparation phase, and store essential goods in advance [9]. Also, important during-disaster measures are transferring injured people to health centers and hospitals and the distribution of essential goods among the injured people.

The main idea of this research is to provide reliable decision-making for emergency relief logistics planning in a disaster in order to increase the response quality and fairness besides total cost minimization. To this end, we try to consider the most important factors of the problem, such as geographical distribution of the affected points, disaster management centers with the possibility of having different sizes, supply centers for the required goods, emergency/non-emergency medical centers, relief distribution centers, different types of goods and injuries, and different types of vehicles. Here, locational and operational decisions are made concurrently within six different levels in the suggested relief logistics network. Accordingly, the main questions are as follows:

i. How many injured people should be transferred to hospitals?

ii. Is there enough capacity to treat injured people?

iii. How many goods in different types should be delivered to disaster management and relief distribution centers from supply centers?

iv. How many goods in different types should be delivered to relief distribution centers from disaster management centers?

v. How many goods in different types should be 
delivered to vulnerable points from the relief distribution centers?

vi. How can we prevent unmet demands at vulnerable points?

vii. What are the best locations to establish disaster management centers, relief distribution centers, and field hospitals?

The objective of this research is to solve a relief logistics network problem in order to locate distribution and medical centers, distribute relief, and transport injuries under the uncertainty of demand, resources, and costs of distribution and transportation of injuries. In a disaster situation, there is no accurate information on open and blocked routes or the number of injures. Therefore, to gain a more real insight into the actual conditions, the uncertain nature of the corresponding parameters is considered. To efficiently deal with uncertain conditions, the robust optimization approach is applied.

Here, the main contributions of the study are described as follows:

- Providing a comprehensive overview of the fundamental decisions on relief logistics planning: (1) Organization of vehicles for transportation; (2) Determination of the best locations for disaster management centers, relief distribution centers, and field hospitals; (3) Determination of the required flows of goods between different levels of the network; and (4) Identification of the number of injured people transported to field/non-field hospitals;

- Developing a novel robust multi-objective, multivehicle, multi-commodity, multi-level relief logistics mathematical model;

- Considering the diversity of injuries in injured people in affected points;

- Considering the public assistance in the model;

- Applying the interval-based robust optimization technique proposed by Bertsimas and Sim [10] to the model;

- Designing an efficient Non-dominated Sorting Genetic Algorithm-II (NSGA-II) to solve the problem and find Pareto-optimal solutions for the problem;

- Applying the Taguchi design method in order to boost the efficiency of the proposed algorithm and employing the $\varepsilon$-constraint method the exact solution technique to evaluate the performance of the algorithm;

- Examining a real case study to test the applicability of the suggested methodology in the study.

The structure of the paper is as follows. Section 2 provides the literature review. Section 3 presents the problem statement, mathematical formulation, and development of the robust model. Then, the $\varepsilon$-constraint method is introduced to validate the presented model in Section 4. Section 5 describes the NSGA-II as a wellknown multi-objective meta-heuristic algorithm in the literature. Section 6 generates several test problems and provides computational results. In Section 7, case study analysis is carried out to confirm the relevance of the presented model. Eventually, conclusions and suggestions for future research are presented in Section 8 .

\section{Literature review}

Generally, investigations conducted on disaster management can be categorized into two groups of management and technical research. The first group seeks to improve and increase efficiency in disaster management phases by examining qualitative concepts. The second group investigates disaster management and rescue supply chain through a quantitative approach and tries to provide quantitative concepts and models for optimizing and improving the relief supply chain. Most of these research works belong to the phases of preparation and response. The main focus of this section is to review the research carried out on the preparation phase.

One of the first studies of the emergency facility location was conducted by Toregas et al. [11], which used linear programming to solve a set covering problem. Moreover, the model proposed by Knott [12] was one of the first models presented to deal with the issue of disaster response that provided a linear programming model aimed at minimizing shipping costs and maximizing delivered food for bulk food transportation problems. Haghani and Oh [13] presented a model for the delivery of various goods such as foodstuff, clothing, medical supplies, drugs, machines, and human resources in a proficient approach to minimizing mortality through consideration of several types of vehicles for relief operations.

Barbarosoğlu et al. [14] focused on helicopters for the provision of relief during natural disasters. Helicopter routing was used for allocation, routing, and transport throughout the response phase of disaster management. Özdamar et al. [15] presented a multi-period model for goods logistics planning in response to natural disasters for the distribution of goods to distribution centers in damaged areas. A deterministic multi-objective model was presented by Tzeng et al. [16] for the distribution of emergency goods to affected areas by considering three objective functions, including minimizing the total cost, minimizing the total travel time, and maximizing minimum satisfaction during the planning interval. It was solved using a multi-objective fuzzy programming method. A dynamic demand-based relief management model 
was formulated by Sheu [17] for emergency logistics operations under deficient information conditions in huge natural disasters. The model included three stages of data fusion to forecast relief demand, fuzzy clustering to categorize the affected area into groups, and multi-criteria decision making to rank the priority order of groups.

Afshar and Haghani [18] developed an allinclusive model for describing logistical operations in natural disasters. They put forward a mathematical model for controlling relief supply flow on the network. Camacho-Vallejo et al. [19] presented a two-level mathematical programming model for humanitarian logistics to optimize decisions in conjunction with the distribution of post-disaster international aid. In the model, after the occurrence of a disaster, international humanitarian organizations and foreign countries were sending out relief supplies, including drinking water, food, and medicine, in order to help the affected country reduce logistical costs. Meanwhile, they were seeking rapid and effective responsiveness to the needs of people. Thus, they developed a nonlinear mathematical model for these purposes, which was then linearized as a complex integer programming problem.

Recently, Boonmee et al. [20] developed a location optimization model for emergency humanitarian logistics. They studied pre- and post-disaster conditions for locating facilities and included accommodations, storage facilities, distribution centers, and medical centers. Moreover, they examined the applicability of the model to several problems available in the literature. Rodriguez Espindola et al. [21] developed a disaster preparation system by combining a multiobjective optimization model and geographic information systems for multi-level decision making in the event of a disaster. They examined their proposed system for the Mexico flood in 2013 and concluded that the number of government agencies involved was excessive, leading to an increase in the total costs.

Due to the high importance of disaster management uncertainty, many scholars in recent years have concentrated on randomly optimizing disaster relief planning. Barbarosoglu and Arda [22] modeled the uncertainty of relief response through developing a two-stage stochastic programming framework for transportation planning in disaster. They developed the deterministic, multi-commodity, and multi-type transport fleet model presented by Yi and Ozdamar [23] to address the uncertainty in the estimation of resources needed for primary relief supply, the vulnerability of facility provider resources, and durability of communication paths in disaster zones. Bozorgi et al. [24] offered a multi-objective robust stochastic programming model for disaster relief logistics under uncertainty conditions. The parameters of demand, supply, purchase cost, and transportation were dealt with in this research as the indeterminate parameters. The model of distributive justice was considered whose goals included minimizing the total cost and maximizing satisfaction by minimizing the maximum unmet demand. The model was solved using a compromise programming method and applied to a set of scenarios in some areas of Iran.

Najafi et al. [2] investigated the response phase at the time of earthquake. They presented a multiobjective, multi-period, multi-commodity, and multimode model to meet the demand for essential goods and transportation of injured people. First, injured people were transported by vehicles to hospitals and then, the vehicles were used for transportation of goods from warehouses and suppliers to damaged points. Earthquake victims were weighed based on their criticality level. Due to vehicle capacity limitations, most critical victims were prioritized during the transportation of injured people. Each vehicle could transport both injured people to hospitals and goods to damaged locations. The number of injured people, the commodity demand in the earthquake areas, the capacity of suppliers for the required goods, and the capacity of hospitals were uncertain. The priority was to minimize the number of injured people who had not been transferred to the hospital, the second priority was to minimize unmet demand, and the third priority was to minimize the number of required vehicles.

Mohamadi et al. [25] presented a two-objective, non-linear, credibility-based fuzzy programming model for the relief disaster logistics design in which the location of hospitals, patient transportation points, and outpatient relief centers as well as the route of ambulance movement were determined. Relief time was considered as a fuzzy parameter. Finally, the mathematical model was linearly investigated and a hypothetical earthquake in Tehran was considered to evaluate the efficiency of the model. Chen and $\mathrm{Yu}$ [26] examined the temporary facility location based on a network for Emergency Medical Services (EMS) allowing for disaster-induced demand and transportation infrastructure in disaster response. In this research, the transportation infrastructure on which the EMS depended was examined. The purpose of this research was to enhance the effectiveness of post-disaster EMS through integer programming and network-based subdividing for the determination of provisional locations for on-post EMS facilities. They solved the problem in different scales using the Lagrangian Relaxation (LR) method and eventually studied a case study and analyzed the results.

Recently, Manopiniwes and Irohara [27] developed a stochastic optimization model for integrated decisions on relief supply chains: preparedness aimed at disaster response. They showed that time constraints and the availability of relief vehicles might have very significant consequences on the problem objectives. Rabbani et 
al. [28] developed a robust possibilistic programming approach to multi-period hospital evacuation planning problem under uncertainty, taking into account the planning horizon. The goal of their problem was to minimize total evacuation time and the total number of injuries that were not evacuated in each period. Subsequently, they developed two meta-algorithms to solve their proposed problem. Moreover, Vahdani et al. [29] developed a two-stage multi-objective location-routinginventory model for humanitarian logistics network design under uncertainty. Their goal was to minimize total cost and travel time and increase the reliability of relief routes. They applied a robust optimization approach for uncertainty conditions. Ultimately, NSGAII and MOPSO algorithms were proposed to solve the problem.

Zanganeh et al. [30] presented a bi-objective model for humanitarian logistics network design in response to post-disaster. The network fairly distributed resources at the vulnerable points to give relief services. In this paper, the first objective function maximized the lifesaving utility function of damaged people and minimized the consequences of aiding impacted people with delays. Also, they studied the role of rolling time horizon and determined after going through what times, how much of the demand for the damaged points was covered. A bi-objective stochastic mathematical model was suggested by Mohamadi and Yaghoubi [1] to design an EMSs network under disruptions. Moreover, they considered backup services to prevent sudden failures. An earthquake case study was investigated in Tehran by applying the $\varepsilon$-constraint method to solve the model. Samani et al. [31] developed a multi-objective MILP model to design an integrated blood supply chain network for disaster relief under fuzzy demands. To solve the model, the interactive fuzzy solution approach was implemented using the CPLEX solver of GAMS software. They conducted an earthquake real case study problem in Mashhad.

Elluru et al. [32] proposed proactive and reactive models for a disaster-resilient supply chain based on the Location-Routing Problem (LRP) with time windows. They studied the role of risk factors and preventive measures for disaster disruptions. They solved the proposed models using LINGO software by illustrating different case problems. Zhang et al. [33] investigated the possibility of increasing the reliability of the relief supply chain by evaluating a real-case study. They analyzed an integrated model to find a trade-off between reliability and cost using the LINGO software. A multi-level facility location-allocation problem was offered by Shavarani [34] for post-disaster humanitarian relief distribution logistics. He designed a hybrid GA to tackle the problem and demonstrated the applicability of the proposed methodology by investigating a real case study in Tehran. A robust-stochastic model was examined by Salehi et al. [35] to design a blood supply chain for a possible earthquake occurrence in Tehran. They defined different scenarios with different probabilities and solved the model using GAMS software. Mohamadi et al. [9] developed a fuzzy multi-objective stochastic programming mathematical model to analyze a disaster relief logistics network with the telecommunication infrastructure. They gave some heuristic arguments for the Lp-metric method to provide a linearized model and conducted a real case study in Tehran using the CPLEX solver of GAMS software.

A two-phase methodology was suggested by Samani and Hosseini-Motlagh [36] for managing a blood supply chain under uncertainties and possible disruptions. They applied the fuzzy analytic hierarchy process and grey rational analysis in the first phase to find supplementary blood facilities. Furthermore, the second phase included the application of the p-robust formulation in order to control network reliability. The validity of the proposed model was revealed by conducting a real case study in Tehran. Table 1 summarizes the most relevant and recent research works to our study from 2017 to 2019.

Based on the conducted studies in the literature, the presented models on relief facilities location are rarely multi-objective and in most cases, the main goal is to minimize the cost variety. According to the existing literature, there is no research on locating disaster relief and distribution centers or solving a multiobjective locating model in relief logistics to maximize the satisfaction of injured people transferred to health premises, maximize the satisfaction of damaged areas through maximizing goods coverage and relief goods distribution, and minimize the total cost. Taking into account the uncertainty through developing a robust problem optimization model, organizing transport vehicles for goods transportation, and developing multiobjective solution methods will easily cover the gaps in the literature.

To fill in the mentioned gaps in the literature, a robust multi-objective location-allocation planning model for disaster relief is proposed together with an NSGA-II to solve the model. To design the algorithm, the Taguchi method is employed to finetune the parameters. Ultimately, the $\varepsilon$-constraint method and comparison indicators are considered for the evaluation of the performance of the proposed algorithm. Furthermore, to prove the applicability of the presented model and algorithm, a case study is performed in the north of Iran.

\section{Problem statement and mathematical model}

First, the scope of the problem is defined and the 
Table 1. Comparison of the relevant research studies.

\begin{tabular}{|c|c|c|c|c|}
\hline Authors & Year & Title & Main contributions & $\begin{array}{c}\text { Solution } \\
\text { methods/tools }\end{array}$ \\
\hline $\begin{array}{l}\text { Manopiniwes } \\
\text { and Irohara [27] }\end{array}$ & 2017 & $\begin{array}{l}\text { Stochastic optimization model for } \\
\text { integrated decisions on relief } \\
\text { supply chains: Preparedness for } \\
\text { disaster response }\end{array}$ & $\begin{array}{l}\text { Stochastic MILP model, pre- and } \\
\text { post-disaster operations, facility } \\
\text { and stock prepositioning, } \\
\text { evacuation planning, and relief } \\
\text { vehicle planning }\end{array}$ & $\begin{array}{l}\text { Normalised } \\
\text { weighted sum } \\
\text { method }\end{array}$ \\
\hline $\begin{array}{l}\text { Mohamadi and } \\
\text { Yaghoubi }[1]\end{array}$ & 2017 & $\begin{array}{c}\text { A bi-objective stochastic model for } \\
\text { emergency medical services } \\
\text { network design with backup } \\
\text { services for disasters under } \\
\text { disruptions: An earthquake case } \\
\text { study }\end{array}$ & $\begin{array}{c}\text { Bi-objective stochastic } \\
\text { optimization model, backup } \\
\text { services, triage system and } \\
\text { failure probabilities, and case } \\
\text { study }\end{array}$ & $\begin{array}{l}\varepsilon \text {-constraint } \\
\text { method }\end{array}$ \\
\hline Samani et al. [31] & 2018 & $\begin{array}{l}\text { Integrated blood supply chain } \\
\text { planning for disaster relief }\end{array}$ & $\begin{array}{l}\text { Uncertain demand for blood } \\
\text { products, perishability of blood } \\
\text { products, cost and } \\
\text { responsiveness trade-off, and } \\
\text { case study }\end{array}$ & $\begin{array}{l}\text { Two-stage stochastic } \\
\text { programming, possibilistic } \\
\text { programming approaches, } \\
\text { and GAMS software }\end{array}$ \\
\hline Elluru et al. [32] & 2019 & $\begin{array}{l}\text { Proactive and reactive models for } \\
\text { disaster resilient supply chain }\end{array}$ & $\begin{array}{c}\text { Resiliency of disaster supply } \\
\text { chain, concurrent facility location } \\
\text { and vehicle routing, time } \\
\text { windows, facility breakdowns, } \\
\text { and route block }\end{array}$ & LINGO software \\
\hline Zhang et al. [33] & 2019 & $\begin{array}{c}\text { Optimization of humanitarian relief } \\
\text { supply chain reliability: A case } \\
\text { study of the Ya'an earthquake }\end{array}$ & $\begin{array}{c}\text { Reliability and cost trade-off } \\
\text { and case study }\end{array}$ & LINGO software \\
\hline Shavarani [34] & 2019 & $\begin{array}{l}\text { Multi-level facility location- } \\
\text { allocation problem for post- } \\
\text { disaster humanitarian relief } \\
\text { distribution }\end{array}$ & $\begin{array}{l}\text { Refuel stations for vehicles, } \\
\text { multi-level facility location- } \\
\text { allocation, and case study }\end{array}$ & Hybrid GA \\
\hline Salehi et al. [35] & 2019 & $\begin{array}{l}\text { Developing a robust stochastic } \\
\text { model for designing a blood supply } \\
\text { chain network in a crisis: A } \\
\text { possible earthquake in Tehran }\end{array}$ & $\begin{array}{l}\text { A robust two-stage multi-period } \\
\text { stochastic model, uncertain } \\
\text { demand, the possibility of } \\
\text { transfusion of one blood } \\
\text { type, and case study }\end{array}$ & GAMS software \\
\hline Mohamadi et al. [9] & 2019 & $\begin{array}{l}\text { Fuzzy multi-objective stochastic } \\
\text { programming model for disaster } \\
\text { relief logistics considering } \\
\text { telecommunication infrastructures: } \\
\text { a case study }\end{array}$ & $\begin{array}{c}\text { Telecommunication } \\
\text { infrastructure, a fuzzy scenario- } \\
\text { based optimization model, case } \\
\text { study, and failure probabilities in } \\
\text { the routes }\end{array}$ & GAMS software \\
\hline $\begin{array}{l}\text { Samani and } \\
\text { Hosseini- } \\
\text { Motlagh [36] }\end{array}$ & 2019 & $\begin{array}{l}\text { An enhanced procedure for } \\
\text { managing blood supply chain } \\
\text { under disruptions and } \\
\text { uncertainties }\end{array}$ & $\begin{array}{c}\text { Disruptions and uncertainties, } \\
\text { case study, and lifetimes and } \\
\text { perishability of blood }\end{array}$ & $\begin{array}{l}\text { Two-phase hybrid } \\
\text { methodology and } \\
\text { GAMS software }\end{array}$ \\
\hline This paper & 2020 & $\begin{array}{l}\text { Multi-objective robust } \\
\text { mathematical modeling for } \\
\text { emergency relief in disaster } \\
\text { under uncertainty }\end{array}$ & $\begin{array}{c}\text { Multi-objective robust } \\
\text { optimization model, demand } \\
\text { uncertainty, public donations, } \\
\text { multiple vehicles, } \\
\text { and case study }\end{array}$ & $\begin{array}{c}\text { The } \varepsilon \text {-constraint } \\
\text { method and } \\
\text { NSGA-II algorithm }\end{array}$ \\
\hline
\end{tabular}



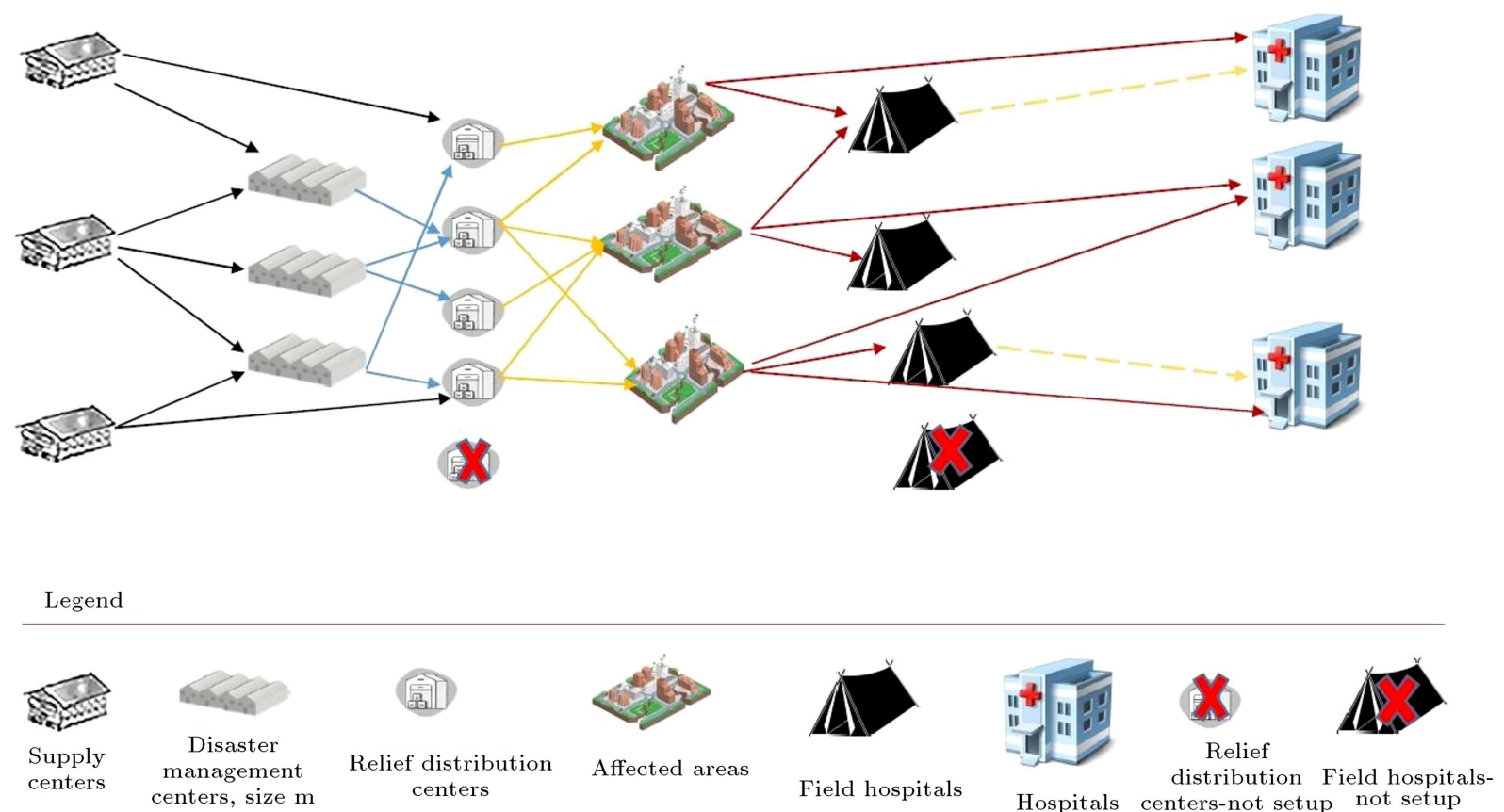

Figure 1. The proposed relief network.

mathematical modeling is presented. Consider a country in which some entities have to provide relief and emergency supplies at the time of disaster. These entities need to consider the pre-disaster potential and capabilities for effective planning and post-disaster relief. For this reason, there are several levels in the country for designing a disaster relief network, including a set of affected areas, a complex of disaster management centers with different capacities, a set of supply centers, a set of medical centers, a set of emergency medical centers, and a set of relief distribution centers. On the other hand, the resources needed to help injured people include a set of essential goods and a set of various vehicles.

Due to the stochastic nature of the majority of the important parameters in planning and logistics due to uncertainties in the type and extent of injuries occurring during a disaster, the parameters of the number of needed goods and the number of injured people are treated as uncertain parameters.

Regarding the newly established depots before the distribution centers in the model, it should be noted that:

- Backup depots hold inventory;

- Different sizes are candidates at different costs;

- Depots have an initial inventory and if needed, further purchase is made based on the model mechanism;

- Depots reduce the risk of commodity shortages or price fluctuations in crisis;
- Batching of goods is done as needed (based on close feedback from distribution agents);

- Popular assistance is provided;

- Depots are interfaces between supply and relief distribution;

- Depots are pre-located in suitable locations (facilities provided and access to roads, dry roads, etc.);

- Depots prevent inappropriate or unnecessary distribution and invasion of people;

- Optimizing the consumption of the existing resources and conserving them in times of crisis lead to less waste;

- Better and closer identification of real requirements is achieved through closer communication with the distribution agents.

An illustration of the proposed relief network is given in Figure 1.

The indices, sets, parameters, and variables of the presented model are described below:

\section{Indices:}

$Z \quad$ Set of points affected by the event, $z \in Z$

$D \quad$ Set of disaster management centers, $d \in D$

$S \quad$ Set of supply centers, $s \in S$

$H \quad$ Set of medical centers, $h \in H$

$E \quad$ Set of emergency medical centers (field hospital), $e \in E$ 


$$
\begin{array}{ll}
G & \text { Set of relief distribution centers , } g \in G \\
K & \text { Set of goods types, } k \in K \\
I & \text { Set of injury types, } i \in I \\
V & \text { Set of vehicle types, } v \in V \\
M & \text { Set of sizes for disaster management } \\
& \text { centers, } m \in M
\end{array}
$$

\section{Parameters:}

$G O_{k z} \quad$ Number of $k$-type goods needed at the vulnerable point $z$

$N I_{i z} \quad$ Number of injured people type $i$ at vulnerable point $z$

$G S_{k s} \quad$ Number of $k$-type goods available at the supply center $s$

$I N I_{d k} \quad$ Initial commodity inventory of type $k$ at the disaster management center $d$

$\omega_{k z} \quad$ Minimum percentage of $k$-type goods that should be provided in the affected area $z$

$W C a_{v} \quad$ Weight capacity of vehicle type $v$

$V C a_{v} \quad$ Volume capacity of vehicle type $v$

$W e_{k} \quad$ Unit weight of $k$-type goods

$V o_{k} \quad$ Unit volume of $k$-type goods

$H C a_{h i} \quad$ Hospital capacity $h$ for type $i$ injuries

$E C a_{e i} \quad$ Capacity of field hospital $e$ for type $i$ injuries

$D C a_{d m k} \quad$ Capacity of disaster management center $d$ with size $m$ for commodity type $k$

$G C a_{g k} \quad$ Capacity of the relief distribution center $g$ for the commodity type $k$

$S C D_{d m} \quad$ Establishment cost of disaster management center $d$ of size $m$

$S C G_{g} \quad$ Establishment cost of relief distribution center $g$

$S C E_{e} \quad$ Establishment cost of field hospital $e$

$\pi_{k z} \quad$ Slack cost per unit for the goods of type $k$ at the vulnerable point $z$

$D T S D_{s d} \quad$ Distance from the supply center $s$ to the disaster management center $d$

$D T S G_{s q} \quad$ Distance from the supply center $s$ to the relief distribution center $g$

$D T G Z_{g z} \quad$ Distance from the relief distribution center $g$ to the vulnerable point $z$

$D T D G_{d g} \quad$ Distance from the disaster management center $d$ to the relief distribut center $g$

$T C_{k v} \quad$ Transporting cost of $k$-type goods by vehicle $v$ per $\mathrm{km}$

$T H_{z h} \quad$ Transporting cost of an injured person from vulnerable point $z$ to hospital $h$
$T E_{z e} \quad$ Transporting cost of an injured person from vulnerable point $z$ to the hospital $e$

$C G O_{k s} \quad$ Cost of purchasing of $k$-type goods from supply center $s$

$N U V_{v s} \quad$ Number of $v$-type vehicles available at supply center $s$

$N U V_{v d} \quad$ Number of $v$-type vehicles available at the disaster management center $d$

$N U V_{v g} \quad$ Number of $v$-type vehicles available at the relief distribution center $g$

$N U A_{z} \quad$ Number of available ambulances at vulnerable point $z$

$A C a \quad$ Ambulance capacity

$P D_{d k} \quad$ Popular donations of $k$-type goods sent to the disaster management center $d$

$P_{i} \quad$ Weighting coefficient for the service priority to the injured people type $i$

Q Big number

Variables:

NIE $E_{i z e} \quad$ Number of $i$-type injured people transferred from vulnerable point $z$ to field hospital $e$

$N I H_{i z h} \quad$ Number of $i$-type injured people transferred from vulnerable point $z$ to hospital $h$

$X O S D_{s d k v} \quad$ Number of transferred $k$-type goods from the supply center $s$ to the disaster management center $d$ by vehicle $v$

$X O S G_{s g k v} \quad$ Number of transferred $k$-type goods from the supply center $s$ to the relief distribution center $g$ by vehicle $v$

$X O D G_{d g k v}$ Number of transferred $k$-type goods from the disaster management center $d$ to the relief distribution center $g$ by vehicle $v$

$X O G Z_{g z k v} \quad$ Number of transferred $k$-type goods from the relief distribution center $g$ to the vulnerable point $z$ by vehicle $v$

$U_{k z} \quad$ Unmet demand for $k$-type goods at vulnerable point $z$

$I D_{d m} \quad$ Binary variable to define whether the $m$-size disaster management center $d$ is established or not

$I E_{e} \quad$ Binary variable to define whether the field hospital $e$ is established or not 
$I G_{g}$

Binary variable to define whether the relief distribution center $g$ is established or not.

Now, the mathematical model is described below:

$\operatorname{Max} Z_{1}=$

$$
\sum_{i} \sum_{z} \min \left[\frac{p_{i} \sum_{e} \sum_{h}\left(N I E_{i z e}+N I H_{i z h}\right)}{N I_{i z}}\right]_{(1)}
$$

$\operatorname{Max} Z_{2}=\sum_{k} \sum_{z} \min \left[\frac{\sum_{g} \sum_{v} X O G Z_{g z k v}}{G O_{k z}}\right]$

$\operatorname{Min} Z_{3}=\sum_{d} \sum_{m} S C D_{d m} \times I D_{d m}+\sum_{g} S C G_{g}$

$\times I G_{g}+\sum_{e} S C E_{e} \times I E_{e}$

$+\sum_{s} \sum_{d} \sum_{k} \sum_{v} T C_{k v} \times D T S D_{s d}$

$\times X O S D_{s d k v}+\sum_{s} \sum_{g} \sum_{k} \sum_{v} T C_{k v}$

$\times D T S G_{s g} \times X O S G_{s g k v}$

$+\sum_{d} \sum_{g} \sum_{k} \sum_{v} T C_{k v} \times D T D G_{d g}$

$\times X O D G_{d g k v}+\sum_{g} \sum_{z} \sum_{k} \sum_{v} T C_{k v}$

$\times D T G Z_{g z} \times X O G Z_{g z k v}$

$+\sum_{i} \sum_{z} \sum_{e} T E_{z e} \times N I E_{i z e}$

$+\sum_{i} \sum_{z} \sum_{h} T H_{z h} \times N I H_{i z h}$

$+\sum_{s} \sum_{d} \sum_{k} \sum_{v} C G O_{k s} \times X O S D_{s d k v}$

$+\sum_{s} \sum_{g} \sum_{k} \sum_{v} C G O_{k s} \times X O S G_{s g k v}$

$+\sum_{z} \sum_{k} \pi_{k z} \times U_{k z}$

s.t.:

$\sum_{d} \sum_{v} X O S D_{s d k v}+\sum_{g} \sum_{v} X O S G_{s g k v} \leq G S_{k s}$

$\forall s \in S, \quad k \in K$,

$$
\begin{gathered}
\sum_{s} \sum_{v} X O S D_{s d k v}+I N I_{d k}+P D_{d k} \leq D C a_{d m k} \\
\forall d \in D, \quad k \in K, \quad m \in M,
\end{gathered}
$$

$\sum_{s} \sum_{v} X O S D_{s d k v}+I N I_{d k}+P D_{d k}$

$\geq \sum_{g} \sum_{v} X O D G_{d g k v} \quad \forall d \in D, \quad k \in K$,

$\sum_{d} \sum_{v} X O S D_{d g k v}+\sum_{s} \sum_{v} X O S G_{s g k v} \leq G C a_{g k}$

$\forall g \in G, \quad k \in K$

$\sum_{s} \sum_{v} X O S G_{s g k v}+\sum_{d} \sum_{v} X O D G_{d g k v}$

$\geq \sum_{z} \sum_{v} X O G Z_{g z k v} \quad \forall g \in G, \quad k \in K$,

$\left(\sum_{g} X O S G_{s g k v}+\sum_{d} X O S D_{s d k v}\right) \times W e_{k}$

$\leq W C a_{v} \times N U V_{v s} \quad \forall s \in S, \quad k \in K, \quad v \in V$,

$\sum_{g} X O D G_{d g k v} \times W e_{k} \leq W C a_{v} \times N U V_{v d}$

$\forall d \in D, \quad k \in K, \quad v \in V$

$\sum_{z} X O G Z_{g z k v} \times W e_{k} \leq W C a_{v} \times N U V_{v g}$

$\forall g \in G, \quad k \in K, \quad v \in V$,

$$
\begin{aligned}
& \left(\sum_{d} X O S D_{s d k v}+\sum_{g} X O S G_{s g k v}\right) \times V o_{k} \\
& \quad \leq V C a_{v} \times N U V_{v s} \quad \forall s \in S, \quad k \in K, \quad v \in V,
\end{aligned}
$$

$\sum_{g} X O D G_{d g k v} \times V o_{k} \leq V C a_{v} \times N U V_{v d}$

$\forall d \in D, \quad k \in K, \quad v \in V$,

$\sum_{z} X O G Z_{g z k v} \times V o_{k} \leq V C a_{v} \times N U V_{v g}$

$\forall g \in G, \quad k \in K, \quad v \in V$,

$\sum_{i} \sum_{h} N I H_{i z h}+\sum_{i} \sum_{e} N I E_{i z e} \leq N U A_{z} \times A C a$

$\forall z \in Z$, 


$$
\begin{aligned}
& X O G Z_{g z k v} \leq Q \times I G_{g} \\
& \forall g \in G, \quad z \in Z, \quad k \in K, \quad v \in V, \\
& X O D G_{d g k v} \leq Q \times I G_{g} \\
& \forall d \in D, \quad g \in G, \quad k \in K, \quad v \in V,
\end{aligned}
$$

$$
X O D G_{d g k v} \leq Q \times I D_{d m}
$$$$
\forall d \in D, \quad g \in G, \quad k \in K, \quad v \in V, \quad m \in M,
$$

$$
\begin{aligned}
& X O S D_{s d k v} \leq Q \times I D_{d m} \\
& \quad \forall s \in S, \quad d \in D, \quad k \in K, \quad v \in V, \quad m \in M,
\end{aligned}
$$

$$
\begin{aligned}
& X O S G_{s g k v} \leq Q \times I G_{g} \\
& \quad \forall s \in S, \quad g \in G, \quad k \in K, \quad v \in V,
\end{aligned}
$$

$$
\begin{aligned}
& N I E_{i z e} \leq Q \times I E_{e} \quad \forall i \in I, \quad z \in Z, \quad e \in E \\
& \sum_{z} N I H_{i z h} \leq H C A_{h i}, \quad \forall i \in I, \quad h \in H \\
& \sum_{z} N I E_{i z e} \leq E C A_{e i} \quad \forall i \in I, \quad e \in E
\end{aligned}
$$$$
\sum_{e} \sum_{h}\left(N I H_{i z h}+N I E_{i z e}\right) \leq N I_{i z}
$$$$
\forall i \in I, \quad z \in Z
$$

$$
G O_{k z}-\sum_{g} \sum_{v} X O G Z_{g z k v} \leq U_{k z}
$$$$
\forall k \in K, \quad z \in Z,
$$

$$
\begin{gathered}
\sum_{g} \sum_{v} X O G Z_{g z k v} \geq \omega_{k z} \times G O_{k z} \\
\forall k \in K, \quad z \in Z,
\end{gathered}
$$

$$
\begin{aligned}
& X O G Z_{g z k v}, X O S D_{s d k v}, X O S G_{s g k v}, X O D G_{d g k v} \\
& N I H_{i z h}, N I E_{i z e} \geq 0, \text { integer }
\end{aligned}
$$$$
I D_{d m}, I E_{e}, I G_{g} \in\{0,1\} \text {. }
$$

Objective Function (1) describes fair servicing to the injured people, which maximizes the minimum service to injured people at vulnerable points. Objective Function (2) refers to the fairness of commodity crisis management, which maximizes the minimum commodity crisis management in vulnerable areas. Objective Function (3) refers to the minimization of costs, including the establishment costs of disaster management centers, relief distribution centers, and field hospitals; costs of transporting to affected areas; costs of displacing injured people and purchasing goods; and costs of goods shortages in the affected area. Eq. (4) represents the number of goods leaving supply centers and the total supply capacity of these centers. Eq. (5) represents the total goods sent to disaster management centers and their capacities. Eq. (6) represents the delivery of goods from disaster management centers to relief distribution centers.

Eq. (7) represents the total goods sent to relief distribution centers and the capacities of these centers. Eq. (8) refers to the goods sent to the relief distribution centers and the goods leaving those warehouses. Eqs. (9)-(11) represent a weight limit for transferring goods, taking into account the number of vehicles. Eqs. (12)-(14) represent the volumetric limit for transferring goods, taking into account the number of vehicles. Eq. (15) is the capacity limit for available ambulances. Eqs. (16)-(21) indicate the relocation of goods in case of establishing disaster management centers, relief distribution centers, or field hospitals. Eqs. (22) and (23) indicate transferring injured people to hospitals and field hospitals and their capacities, respectively. Eqs. (24) and (25) represent demand and servicing, respectively. Eq. (26) represents the minimum demand that needs to be met. Eq. (27) specifies the type of the variables.

\subsection{Robust counterpart model}

Robust optimization techniques search for nearoptimal solutions to keep their feasibility with a high probability [37]. The guarantee the feasibility by restricting the obtained optimal value for the objective function to a small possible limit under an uncertain situation. Bertsimas and Sim [10] introduced an efficient linear interval-based methodology to control the conservatism level of the solutions under uncertain conditions, which has been then investigated by many researchers in different fields of optimization [38-41]. Adarang et al. [42] formulated a LRP using a robust optimization approach. In this research, the number of patients was uncertain and the robust counterpart of the problem was developed by the robust method of Bertsimas and Sim [10]. Samani et al. [43] studied blood supply chain networks with uncertain demands and supplies. They used robust and fuzzy approaches to dealing with uncertainty. Erbeyoğlu and Bilge [44] surveyed the robustness of demand in a disaster preparedness model. They utilized a robustness approach, which ensured the feasibility of the problem and addressed the uncertainty of the problem with a representative set of disaster scenarios. Haeri et al. [45] employed a robust optimization approach for a blood supply chain network. Due to the uncertain nature 
and irregular donation of blood, a particular kind of two-stage stochastic-robust programming introduced by Aghezzaf et al. [46] was used. Ahmadi et al. [47] proposed a new robust decision support framework for Search And Rescue (SAR) operations in the disaster response phase. They used an interval-based robust optimization approach to tackling the uncertainty and solved a case study under an earthquake scenario in Tehran, Iran.

Our suggested model is developed based on the Bertsimas and Sim's approach to addressing the demand uncertainty. The proposed framework of the robust counterpart model by Bertsimas and Sim [10] is given as follows. Consider the following optimization problem:

$\operatorname{Min} C^{T} x$,

$$
\text { s.t.: }
$$

$$
A x \leq b \quad l \leq x \leq u .
$$

Now, assume that $C^{T}$ and $A$ constitute the uncertain parameters of the model. Therefore, uncertainty intervals are considered as $\left[c_{j}-d_{j}, c_{j}+d_{j}\right]$ and $\left[a_{i j}-\widehat{a_{i j}}, a_{i j}+\widehat{a_{i j}}\right]$ for $C^{T}$ and $A$, respectively. Here, $d_{j}$ and $\hat{a}_{i j}$ represent the deviation levels from the average values of parameters $c_{j}$ and $a_{i j}$, respectively. The final robust model is given by implementing the required transformations based on Bertsimas and Sim [10].

To develop the robust counterpart model of this study, the parameters $G O_{k z}$ and $N I_{i z}$ are affected by uncertainty. These parameters are defined in an uncertainty interval as $\left(\left[\widetilde{G O}_{k z}-\widehat{G O}_{k z}, \widetilde{G O}_{k z}+\right.\right.$ $\left.\left.\widehat{G O}_{k z}\right]\right)$ for the required $k$-type goods and as $\left(\left[\widehat{N I}_{i z}\right.\right.$ $\left.\left.-\widehat{N I}_{i z}, \widetilde{N I}_{i z}+\widehat{N I}_{i z}\right]\right)$ for the number of $i$-type injured people at the vulnerable point $z$, respectively, based on the Bertsimas and Sim approach. Given the interval uncertainty, each uncertain value of $G O_{k z}$ is in the form of a symmetric and limited interval centered on $\widehat{G O}_{k z}$ as $\widehat{G O}_{k z}=\alpha \widehat{G O}_{k z}$, where $\widetilde{G O}_{k z}$ is the estimated value of the demand parameter, $\widehat{G O}_{k z}$ the amount of demand fluctuations, and $\alpha \succ 0$ the uncertainty level of this parameter. In this way, for each value, $N I_{i z}$ is in the form of a symmetric and limited interval centered on $\widehat{N I}_{i z}=\beta \widetilde{N I}_{i z}$, where $\widetilde{N I}_{i z}$ refers to the estimated value of demand parameter, $\widehat{N I}_{i z}$ the oscillation of demand parameter, and $\beta \succ 0$ the uncertainty level for this parameter.

Objective Functions (1) and (2) and Constraints (24)-(26) lead to a robust problem based on the proposed Bertsimas and Sim model. These restrictions are in non-robust form in the deterministic model. To provide the robust counterpart of the proposed model, Eqs. (29), (31), (33), (30), (32), and (34)-(40) are added [10]. The deterministic model changes to the robust counterpart model by the Bertsimas and Sim approach as follows. The uncertainty parameters are in both the constraints and the objective function. They are given regarding the maximization objective function:

$\operatorname{Max} Z_{1}=$

$$
\begin{aligned}
& \sum_{i} \sum_{z} \min \left[\frac{p_{i} \sum_{e} \sum_{h}\left(N I E_{i z e}+N I H_{i z h}\right)}{\widetilde{N} I_{i z}}\right. \\
& \left.-Z^{\prime}{ }_{0} \Gamma^{\prime}{ }_{0}-\sum_{e} \sum_{h} r^{\prime}{ }_{0 i z e h}\right]
\end{aligned}
$$

$$
\begin{gathered}
\operatorname{Max} Z_{2}=\sum_{k} \sum_{z} \min \left[\frac{\sum_{g} \sum_{v} X O G Z_{g z k v}}{\widetilde{G O}_{k z}}\right. \\
\left.-Z^{\prime \prime}{ }_{0} \Gamma^{\prime \prime}{ }_{0}-\sum_{g} \sum_{v} r^{\prime \prime}{ }_{0 g z k v}\right],
\end{gathered}
$$

$$
\begin{gathered}
Z_{0}^{\prime}+r_{0 i z e h}^{\prime} \geq \mu_{i z} E 1_{i z} \quad \forall i \in I, \quad z \in Z, \\
Z_{0}^{\prime \prime}+r_{0 g z v}^{\prime \prime} \geq \mu_{k z} E 2_{k z} \quad \forall k \in K, \quad z \in Z, \\
-E 1_{i z} \leq N I E_{i z e}+N I H_{i z h} \leq+E 1_{i z} \\
\forall i \in I, \quad z \in Z, \quad e \in E, \quad h \in H, \\
-E 2_{k z} \leq X O G Z_{g z k v} \leq+E 2_{k z} \\
\forall g \in G, \quad z \in Z, \quad k \in K, \quad v \in V
\end{gathered}
$$

$\sum_{e} \sum_{h}\left(N I H_{i z h}+N I E_{i z e}\right) \leq \widetilde{N I} \widetilde{I z}_{i z}-Z 1_{i z} \Gamma 1_{i z}$

$$
-\sum_{e} \sum_{h} r 1_{i z e h} \quad \forall i \in I, \quad z \in Z,
$$

$$
Z 1_{i z}+r 1_{i z e h} \geq \widetilde{N I}_{i z} E 1_{i z} \quad \forall i \in I, \quad z \in Z,
$$

$$
\begin{gathered}
\widetilde{G O}_{k z}+Z 2_{k z} \Gamma 2_{k z}+\sum_{g} \sum_{v} r 2_{k z}-\sum_{g} \sum_{v} X O G Z_{g z k v} \\
\leq U_{k z} \quad \forall k \in K, \quad z \in Z, \\
Z 2_{k z}+r 2_{k z} \geq \widetilde{G O}_{k z} E 2_{k z} \quad \forall k \in K, \quad z \in Z, \quad(38) \\
\sum_{g} \sum_{v} X O G Z_{g z k v} \geq \omega_{k z} \times \\
\left(\widetilde{G O}_{k z}+Z 2_{k z} \Gamma 2_{k z}+\sum_{g} \sum_{v} r 2_{k z}\right)
\end{gathered}
$$

$\forall k \in K, \quad z \in Z$, 


$$
\begin{gathered}
Z 1_{i z}, Z 2_{k z}, r 1_{i z}, r 2_{k z}, E 1_{i z}, E 2_{k z}, Z_{0}^{\prime}, r_{0 i z e h}^{\prime}, \\
Z_{0}^{\prime \prime}, r_{0 g z v}^{\prime \prime} \geq 0, \quad \mu_{k z}, \mu_{i z} \in[0,1] .
\end{gathered}
$$

Finally, a robust model is developed by considering the following constraints: Eqs. (29), (31), (33), (30), (32), (34), (3)-(23), (35)-(36), (37)-(38), (39), (27), and (40).

\section{4. $\varepsilon$-constraint method}

The $\varepsilon$-constraint method is among the well-known multi-objective solution techniques used in a wide range of applications by Bérubé et al. [48]. In this method, for multi-objective problems, constraints are treated through transferring all objective functions except one of them at each step. The Pareto frontier can be created by the $\varepsilon$-constraint method. The basic model of this method is given as follows [48]:

$$
\begin{aligned}
& \min f_{1}(X), \\
& \text { s.t.: } \\
& x \in X, \\
& f_{2}(X) \leq \varepsilon_{2}, \\
& \cdots \\
& f_{n}(X) \leq \varepsilon_{n} .
\end{aligned}
$$

The main steps of the proposed $\varepsilon$-constraint method are given below:
1. Each time, select an objective function as the primary objective function;

2. According to the selected objective function, solve the problem and obtain optimal values for each objective function;

3. Divide the interval of two optimal values of the sub-objective functions by a predefined number and obtain values for $\varepsilon_{2}, \ldots, \varepsilon_{n}$;

4. Each time, solve the problem with the main objective function with any of the values $\varepsilon_{2}, \ldots, \varepsilon_{n}$;

5. Report the obtained Pareto solutions.

To validate the proposed model in a small size, an example is generated and the information is given in Table 2. Then, GAMS software using the BARON solver is applied to use the $\varepsilon$-constraint method for a deterministic problem. Also, parameter values are randomly determined using uniform distribution in the software (see Table 2).

In the problem presented in this research, the first objective function is assumed as the main objective function. Moreover, 10 breakpoints are considered in the problem. Data for the designed example network is given in Table 3 .

After solving the problem, one of the Pareto boundaries obtained according to the experts is selected as the output of the problem as shown in Table 4.

Table 2. Distribution function of input parameters for the example problem.

\begin{tabular}{cccc}
\hline$G O_{k z}$ & Round (uniform $(1,5))$ & $\pi_{k z}$ & Uniform $(100,200)$ \\
$N I_{i z}$ & Round (uniform $(6,24))$ & $D T S D_{s d}$ & Uniform $(3,12)$ \\
$G S_{k s}$ & Round (uniform $(200,260))$ & $D T S G_{s g}$ & Uniform $(3,12)$ \\
$I N I_{d k}$ & Round (uniform $(20,26))$ & $D T G Z_{g z}$ & Uniform $(3,12)$ \\
$\omega$ & Uniform $(0.1,0.2)$ & $D T D G_{d g}$ & Uniform $(3,12)$ \\
$W C a_{v}$ & Uniform $(500,1000)$ & $T C_{k v}$ & Uniform $(1,5)$ \\
$V C a_{v}$ & Uniform $(3000,8000)$ & $T H_{z h}$ & Uniform $(1,5)$ \\
$W e_{k}$ & Uniform $(5,10)$ & $T E_{z e}$ & Uniform $(1,5)$ \\
$V o_{k}$ & Uniform $(30,80)$ & $C G O_{k s}$ & Uniform $(12,52)$ \\
$H C a_{h i}$ & Round (uniform $(500,600))$ & $N U V_{v s}$ & Round (uniform $(2,10))$ \\
$E C a_{e i}$ & Round (uniform $(100,200))$ & $N U V_{v d}$ & Round (uniform $(2,10))$ \\
$D C a_{d m k}$ & Round (uniform $(4000,6000))$ & $N U V_{v g}$ & Round (uniform $(4,6)$ ) \\
$G C a_{g k}$ & Uniform $(600,800)$ & $N U A_{z}$ & Round (uniform $(1,2)$ ) \\
$S C D_{d m}$ & Uniform (100000,200000) & $A C a$ & Round (uniform $(4,6)$ ) \\
$S C G_{g}$ & Uniform $(50000,100000)$ & $P D_{d k}$ & Round (uniform $(100,1000)$ ) \\
$S C E_{e}$ & Uniform $(10000,20000)$ & $\alpha$ & 0.25 \\
$P 1$ & 0.35 & $\beta$ & 0.25 \\
$P 2$ & 0.65 & $\Gamma_{0}^{\prime}$ & 1 \\
$\Gamma 22_{k z}$ & 0.5 & $\Gamma 1_{i z}^{\prime \prime}$ & 0.5 \\
$\mu_{i z}, \mu_{k z}$ & 0.25 & & 1 \\
\hline
\end{tabular}


Table 3. Data of the designed example network.

\begin{tabular}{cc}
\hline Sets & Number \\
\hline$Z$ & 8 \\
$D$ & 3 \\
$S$ & 2 \\
$H$ & 3 \\
$E$ & 4 \\
$G$ & 3 \\
$K$ & 2 \\
$I$ & 2 \\
$V$ & 3 \\
$M$ & 2 \\
\hline
\end{tabular}

\section{Non-dominated Sorting Genetic Algorithm (NSGA-II)}

The NSGA-II is a common optimization algorithm for the multi-objective optimization introduced by Deb et al. [49]. A Genetic Algorithm (GA) is a well-known meta-heuristic algorithm used for problems related to the supply chain certification. This algorithm is known for its great power in obtaining solutions to problems, especially those such as the intended problem, which include a very large state space impossible to be examined in all of its modes by humans. In other words, the speed of this algorithm in moving toward the solution to the problem is one of the positive points of this algorithm. Another positive feature of this algorithm is that, unlike other algorithms that search the problem-solving space in only one direction, it can simultaneously search in multiple directions. No need for the continuity and convexity of the objective function can also be considered as another positive feature of this algorithm. Its weaknesses include time-intensive parameter tuning for parameters such as population size and mutation and crossover operators' rates as well as instability of the solution. By instability, the difference in the quality of the results due to various runs of the algorithm is meant [50]. The flowchart of the proposed NSGA-II is illustrated in Figure 2.

Given the above considerations, the GA has great ability in searching and discovering a wide range of intervals. The components of the GA are as follows:

- Chromosome: At the beginning of a GA solution to a problem, one should associate the problem with the original structure of the GA and a solution space in which the evolution occurs. In a GA and any genetic-based algorithm, each chromosome

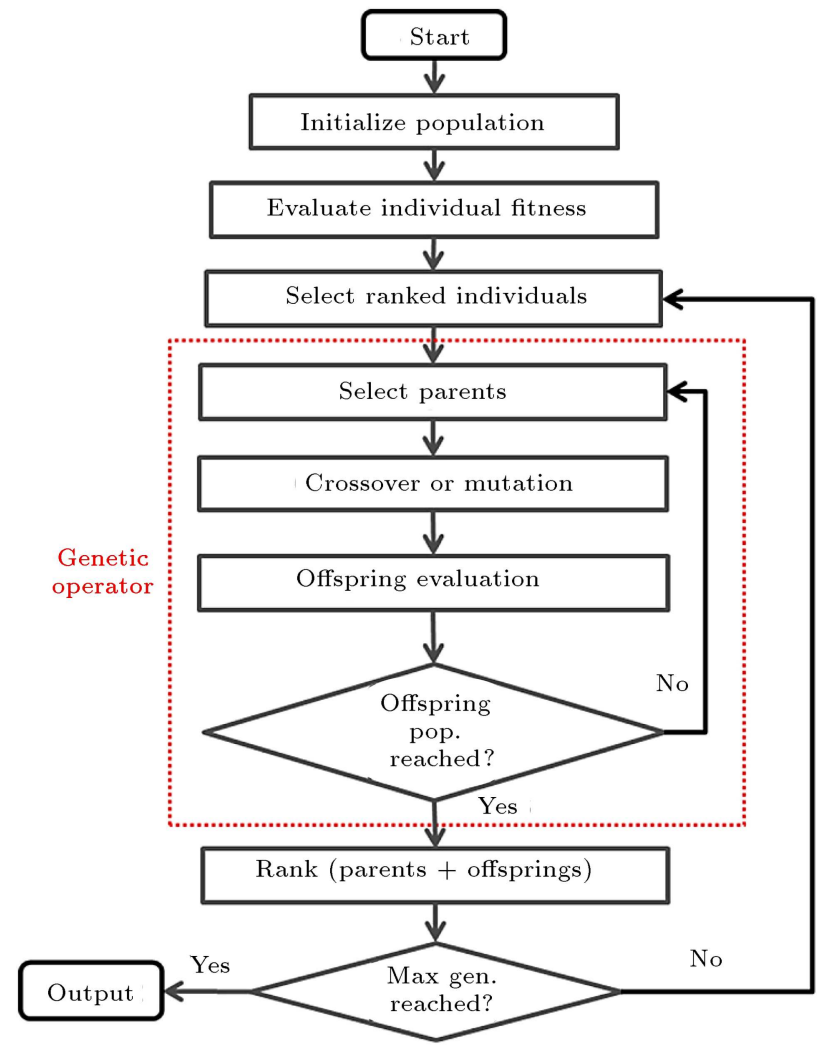

Figure 2. Flowchart of the proposed NSGA-II.

signifies a point of the solution space and a feasible solution, comprising a specific number of genes that can be considered as variables. A chromosome of the population of solutions can be a vector of integer numbers for discrete optimization problems and a vector of real numbers for continuous optimization problems. The most important point here is to choose a chromosome displaying method according to the problem structure in a way that different operators of the algorithm are performed in the shortest possible time.

In the proposed GA, a solution to a matrix with seven rows is used to represent the solution as shown in Figure 3. In the first line of this matrix, there are $I \times Z \times E$ columns indicating the number of $i$-type injured people transferred from vulnerable point $z$ to field hospital $e$. In the second line of the matrix, there are $I \times Z \times H$ columns representing the number of $i$-type injured people transferred from vulnerable point $z$ to hospital $h$.

The third row of the matrix also contains $S \times$ $D \times K \times V$ columns, which indicate the number of $k$-type goods transferred from the supply center $s$ to

Table 4. Output of the random example using the $\varepsilon$-constraint method.

\begin{tabular}{cccc}
\hline Objective function $\mathbf{1}$ & Objective function $\mathbf{2}$ & Objective function $\mathbf{3}$ & CPU time (s) \\
\hline 0.163 & 0.523 & 1656176 & 113.9 \\
\hline
\end{tabular}




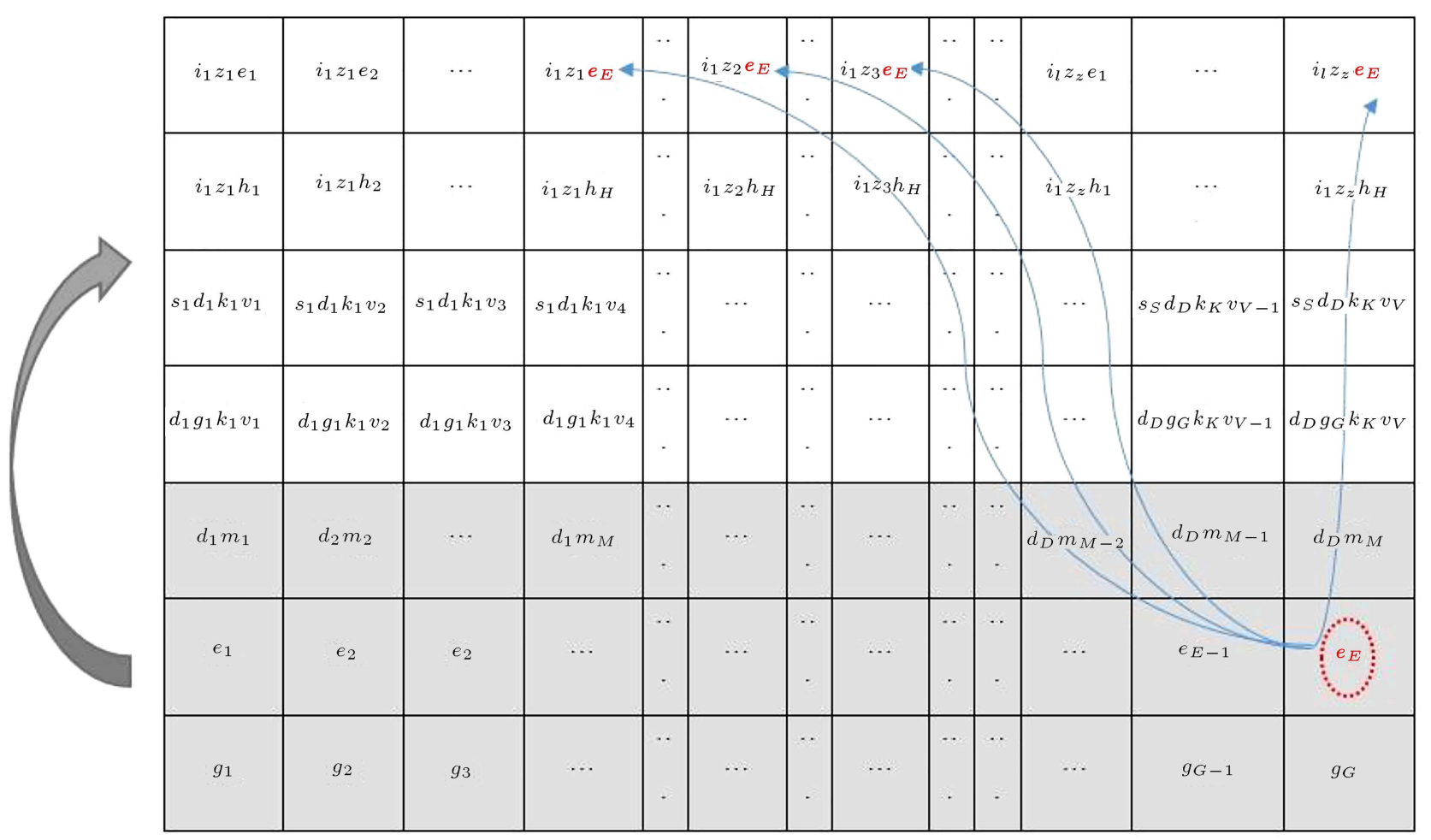

Figure 3. Solution representation in the form of a chromosome for the GA.

the disaster management center $d$ by vehicle $v$. The fourth row of the matrix also has $D \times G \times K \times V$ columns, which show the number of $k$-type goods transferred from the disaster management center $d$ to the relief distribution center $g$ by vehicle $v$. In the fifth row, there are $D \times M$ columns the corresponding cell value of which will be 1 provided establishing a disaster management center $d$ of size $m$ and zero otherwise. In the sixth row, there are $E$ columns the corresponding cell value of which will be 1 provided establishing a field hospital $e$ and zero otherwise. In the seventh row, there are $G$ columns the corresponding cell value of which will be 1 provided establishing a relief distribution center $g$ and zero otherwise.

The mechanism of the solution representation is as follows:

- Random values of 0 and 1 are assigned to the three lowest rows;

- Initial feasibility is checked in a way to take at most one value from each $d_{i}$ (if $d_{l}$ of $m_{2}$ size is equal to 1 , other $d_{1}$ values become zero or take no value) and at least one of them takes value in each row;

- Non-decision variable indices with the value of 1 are given to each cell and other indices corresponding to unit variables (in the three lowest rows) are given the value of 1 ;

- The above-mentioned indices are multiplied;
- Cells of non-zero values are variables that can take values (feasible solution);

- Regarding the constraint mechanisms and the types of variables, integer random numbers are given values between zero and the maximum desired variable;

- Feasibility is re-checked. In case of the existence of a feasible solution, the above and below solutions are deemed a total feasible solution;

- The solution is saved and the process continues up to approaching the stop condition;

- For each unfeasible solution that encroaches the problem constraints, a big value penalty is considered in the fitness function to prevent the continuance of the solution process and put the mechanism in a way to produce better-fitted solutions.

The GA is important because its small values lead to a search in a small part of the solution space and its large values increase the execution time of the algorithm. In the algorithm, the initial solutions for the first generation are randomized. The appropriate population size is given in the next section (parameter tuning).

- Fitness function: This function represents the suitability of each chromosome and selection mechanism is based on this function. In the GA, fitness function can be the main objective function or a simple transformation of it. In the given problem, 


First parent
\begin{tabular}{|l|l|l|l|l|l|l|l|l|l|l|l|}
\hline 1 & 0 & 0 & 0 & 0 & 1 & 1 & 0 & 1 & 1 & 0 & 1 \\
\hline 0 & 0 & 1 & 0 & 1 & 0 & 1 & 0 & 0 & 0 & 0 & 1 \\
\hline
\end{tabular}
\begin{tabular}{|l|l|l|l|c|c|c|c|c|c|c|c|}
\hline 1 & 0 & 0 & 0 & 0 & 0 & 1 & 0 & 0 & 0 & 0 & 1 \\
\hline
\end{tabular}

Figure 4. Example of the crossover operator performance.

the fitness function for each chromosome in each generation is considered equal to the value of the objective function problem.

- Selection mechanism: At this stage, several superior chromosomes are chosen as parents for reproduction. The best chromosomes are selected based on the degree of fitness. Importantly, chromosomes of less fitness are less likely, but likely to be parents anyway. Among the most common choices are the Roulette Wheel, Tournament, Random, and Ranking.

- Crossover operator: This operator is the most important feature of the algorithm by which from two or more selective parents, one or more children (new solutions) are generated. This operator runs on a percentage of the population so that two parents are selected and a random number is created. The generated random number is compared with the crossover rate and if the rate is lower, two children are generated; otherwise, the parent will be transferred to the next generation without child production. As a result, a new set of solutions includes new solutions and those copied from the previous generations.

The crossover operator in this research is dedicated to rows with the numbers of zero and one (lines 5 to 7 ). Therefore, first, a random number $R$ is selected from zero to all bits. Then, the $R$-bit value is randomly assigned to the first parent and the remaining bits are randomly assigned to the second parent for a child and the child is formed. Note that for a crossover operator on a matrix, each matrix row is considered as a chromosome individually and the above steps are repeated.

For example, assume that $R=5$ is generated and there are two parents. The child produced will be in the form indicated in Figure 4.

- Mutation operator: This operator receives an input value and creates a mutant child to prevent premature convergence of the algorithm to a solution. Like a crossover operator, this operator is performed on a percentage of the population. The type and parameters of mutation are directly related to the display mode of the problem. The mutation rate for this problem is given in the following (parameter

\begin{tabular}{|l|l|l|l|l|l|l|l|l|l|l|l|}
\hline 1 & 0 & 0 & 0 & 0 & 1 & 1 & 0 & 1 & 1 & 0 & 0 \\
\hline 1 & 0 & 0 & 0 & 0 & 1 & 1 & 0 & 1 & 1 & 0 & 1 \\
\hline
\end{tabular}

Figure 5. Example of the mutation operator performance.

tuning). Also, the mutation used in this algorithm is as follows.

For the rows of the binary numbers (lines 5 to 7 ), one bit of chromosome is randomly selected through selecting a random number $R$ from 0 to all the available bits. If the value of the selected bit is zero, it is changed to one and if its initial value is one, it is changed to zero. For example, suppose that $R=12$. Figure 5 shows an example of the mutation operator performance.

- Stopping and preparation criteria: Various terms may be expressed for stopping and ending the algorithm, including the expiration of maximum allowed time for resolution, reaching a certain number of generations, failure to improve the response after several predetermined repetitions, etc. In this research, the stopping criterion is the failure to improve the objective function after 50 repetitions. Preparation refers to determination of the numbers of the initial population, generations, and crossover as well as the rate of mutations, which are different for each problem, as given in the next section (parameter tuning).

Two approaches are used for tuning the NSGAII parameters, including (1) standard ANOVA method (analysis of variance) and (2) Taguchi signal-to-noise $(S / N)$ ratio, which expresses the dispersion around a given value. The method of analysis of variance, despite its simplicity, cannot investigate the dispersion of responses. Therefore, its solution is not accurate in the case experiments. In this research, the $S / N$ ratio is used. For a minimization problem, Taguchi et al. [51] proposed the following equation named as "the smaller the better:"

$$
S / N \text { Ratio }=-10 \log \sum_{i=1}^{k}\left(y_{i}^{2} / k\right),
$$

where $y_{i}$ refers to the performance of the $i$ th experiment and $k$ is the total number of repetitions for the experiment. Maximizing the $S / N$ ratio leads to minimizing the dispersion of objective functions. Taguchi divided the objective functions into three classes: the smaller the better, the larger the better, and nominal is the best.

In the present study, appropriate values of parameters for the algorithm are determined in successive stages with the help of the Minitab software. Three levels of the important parameters are given in Table 5.

Criteria are converted into a single response using 
Table 5. Different levels of the NSGA-II parameters.

\begin{tabular}{cc}
\hline Parameter & Levels \\
\hline Crossover rate & $0.90,0.80,0.70$ \\
Mutation rate & $0.30,0.20,0.10$ \\
Initial population & $300,250,200$ \\
\hline
\end{tabular}

the Simple Additive Weighting (SAW) technique. The SAW technique can be described in several steps:

1. Determine the negative or positive nature of each criterion;

2. Scale the values of criteria in the decision matrix by Eq. (43):

$$
\begin{aligned}
& \text { if } r_{i j}^{+}, n_{i j}=\frac{r_{i j}}{r_{j}^{\max }}, \\
& \text { if } r_{i j}^{-}, n_{i j}=\frac{r_{j}^{\min }}{r_{i j}},
\end{aligned}
$$

where $r_{i j}$ is the value of the combination criterion $i$ in criterion $j$. After normalizing, the criteria become positive.

3. Calculate the SAW in Eq. (44):

$$
S A W_{i}=\sum_{j} w_{j} n_{i j}, \quad \sum_{j} w_{j}=1 .
$$

Therefore, at each of 27 levels, the sample problem was created and solved and the results were introduced into the Minitab software for designing the Taguchi test. Figure 6 shows the results of parameter adjustments.

The best combination for the parameters of NSGA-II given in Table 6 may be determined through

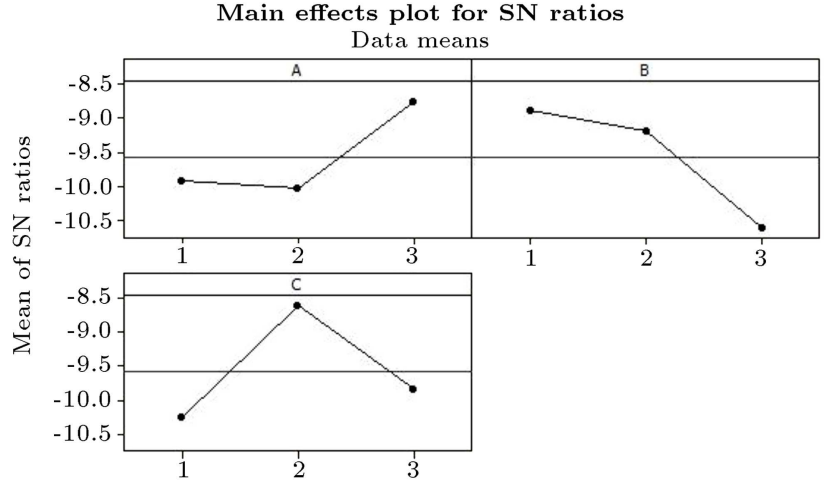

Signal-to-noise: Smaller is better

Figure 6. Parameters adjustment for the NSGA-II.

examining Figure 6. According to this table, values of 0.9 for the crossover rate, 0.10 for the mutation rate, and 250 for the initial population were selected. Also, according to the initial data test, the required number of generations for algorithm improvement was equal to 50 .

\section{Computational results}

To analyze the results of the proposed model, first, an explanation is given about the generation of experimental problems and adjustment of input parameters. Then, we will consider the problem and analyze the results. To solve the problem, we implemented the model for three experimental problems in different dimensions (i.e., small, medium, and large). The size of the designed experiments (problem size) in each of the experiments is given in Table 7 .

Problems are solved in various uncertainty levels and the effect of uncertainty is examined on each

Table 6. Proposed values for the NSGA-II parameters.

\begin{tabular}{|c|c|c|c|c|c|c|c|c|c|c|}
\hline Sample number & $\# \mathbf{Z}$ & $\# \mathbf{D}$ & $\# \mathbf{S}$ & $\# \mathbf{H}$ & $\# \mathbf{E}$ & $\# \mathbf{G}$ & $\# \mathbf{K}$ & $\# \mathbf{I}$ & $\# \mathbf{V}$ & $\# \mathrm{M}$ \\
\hline 1 & 3 & 1 & 1 & 1 & 1 & 1 & 1 & 1 & 1 & 1 \\
\hline 2 & 5 & 1 & 2 & 2 & 1 & 2 & 1 & 1 & 1 & 1 \\
\hline 3 & 8 & 3 & 2 & 3 & 4 & 3 & 2 & 2 & 3 & 2 \\
\hline 4 & 10 & 3 & 3 & 4 & 2 & 3 & 4 & 2 & 2 & 2 \\
\hline 5 & 12 & 4 & 3 & 5 & 3 & 3 & 4 & 3 & 3 & 2 \\
\hline 6 & 15 & 5 & 4 & 5 & 3 & 4 & 6 & 3 & 4 & 2 \\
\hline 7 & 20 & 5 & 4 & 7 & 5 & 5 & 6 & 4 & 4 & 3 \\
\hline 8 & 50 & 7 & 5 & 9 & 10 & 7 & 8 & 4 & 5 & 3 \\
\hline 9 & 100 & 9 & 7 & 10 & 15 & 10 & 8 & 5 & 7 & 4 \\
\hline 10 & 120 & 10 & 12 & 15 & 20 & 15 & 10 & 6 & 10 & 4 \\
\hline
\end{tabular}

\begin{tabular}{cccc}
\hline Crossover rate & Mutation rate & Initial population & Number of generations \\
\hline 0.90 & 0.10 & 250 & 50 \\
\hline
\end{tabular}

Table 7. Number of different levels of sample problems. 
Table 8. Sensitivity analysis of various uncertainty levels.

\begin{tabular}{ccccccc}
\hline $\begin{array}{c}\text { Uncertainty } \\
\text { levels }\end{array}$ & $\begin{array}{c}\text { 1st } \\
\text { objective }\end{array}$ & $\begin{array}{c}\text { 2nd } \\
\text { objective }\end{array}$ & $\begin{array}{c}\text { 3rd } \\
\text { objective }\end{array}$ & $\begin{array}{c}\text { No. of } \\
\text { constructed } \\
\text { disaster } \\
\text { centers }\end{array}$ & $\begin{array}{c}\text { No. of } \\
\text { constructed } \\
\text { field } \\
\text { hospitals }\end{array}$ & $\begin{array}{c}\text { No. of } \\
\text { constructed } \\
\text { distribution } \\
\text { centers }\end{array}$ \\
\hline 0.2 & 0.163 & 0.523 & 1656176 & 2 & 3 & 1 \\
0.4 & 0.160 & 0.511 & 1862187 & 2 & 3 & 2 \\
0.6 & 0.156 & 0.489 & 2338921 & 3 & 3 & 3 \\
0.8 & 0.151 & 0.473 & 2794117 & 3 & 4 & 3 \\
\hline
\end{tabular}

Table 9. Pareto-optimal solution by the $\varepsilon$-constraint method and NSGA-II.

\begin{tabular}{|c|c|c|c|c|c|c|}
\hline \multirow[b]{2}{*}{ No. } & \multicolumn{3}{|c|}{$\varepsilon$-constraint } & \multicolumn{3}{|c|}{ NSGA-II } \\
\hline & $\begin{array}{c}\text { 1st } \\
\text { objective }\end{array}$ & $\begin{array}{c}\text { 2nd } \\
\text { objective }\end{array}$ & $\begin{array}{c}\text { 3rd } \\
\text { objective }\end{array}$ & $\begin{array}{c}\text { 1st } \\
\text { objective }\end{array}$ & $\begin{array}{c}\text { 2nd } \\
\text { objective }\end{array}$ & $\begin{array}{c}\text { 3rd } \\
\text { objective }\end{array}$ \\
\hline 1 & 0.15 & 0.119 & 1563222 & 0.154 & 0.087 & 1592745 \\
\hline 2 & 0.158 & 0.272 & 1598394 & 0.158 & 0.111 & 1626129 \\
\hline 3 & 0.163 & 0.523 & 1656176 & 0.162 & 0.272 & 1664912 \\
\hline 4 & 0.167 & 0.57 & 1708462 & 0.167 & 0.38 & 1703488 \\
\hline 5 & 0.177 & 0.626 & 1771419 & 0.171 & 0.429 & 1736195 \\
\hline 6 & 0.189 & 0.678 & 1837315 & 0.174 & 0.595 & 1754807 \\
\hline 7 & 0.193 & 0.796 & 1888742 & 0.176 & 0.679 & 1801958 \\
\hline 8 & 0.198 & 0.916 & 1911274 & 0.18 & 0.784 & 1851855 \\
\hline 9 & 0.203 & 0.946 & 1937631 & 0.182 & 0.821 & 1889577 \\
\hline 10 & 0.21 & 0.993 & 1979910 & 0.186 & 0.891 & 1913669 \\
\hline 11 & - & - & - & 0.19 & 0.943 & 1942530 \\
\hline 12 & - & - & - & 0.195 & 0.989 & 1967429 \\
\hline
\end{tabular}

objective function. It is worthwhile to mention that the uncertainty budget or conservation levels are given as constant values based on the considered values in Table 8. To this aim, Problem 3 is considered and the computational results are given in the table based on various uncertainty levels. According to this table, the values of first and second objective functions decrease with increase in uncertainty level. We get far from optimal with increase in uncertainty. Therefore, service provision and coverage of relief commodities decrease by increasing uncertainty levels in the problem domain. Moreover, the third objective function shows increase and gets away from optimal due to its minimization nature. Responding to demand bears more costs under higher uncertainty levels. Noteworthy for the following parts of this paper, the uncertainty level is assumed to be equal to 0.2 .

In the following, numerical output of the proposed model through the exact solution and NSGA-II is presented and the obtained results are validated and compared. Problems were run in the CPLEX solver of the GAMS software on an Intel Core i7 laptop ( 8 GB RAM). Then, the results of the NSGA-II were compared with the exact solution results of the model from the CPLEX solver of the GAMS software and the performance of the algorithm was evaluated. It should be noted that the suggested GA in this research was codified using the MATLAB programming language. Moreover, it is worthwhile to mention that the time limit was considered to be 3600 seconds for solving problems by the exact method.

After solving the problems by the $\varepsilon$-constraint method, the problems were solved by NSGA-II. Table 9 presents the results for Problem 3. The Pareto boundaries created for Problems 3 are shown in Figures 7 to 9 . In these figures, it is evident that the proposed Pareto front by the NSGA-II is close to the boundary obtained by the $\varepsilon$-constraint method. However, for more accurate validation of the proposed algorithm and to outline the extent to which this algorithm is applicable, we computed the three indices of Mean Ideal Distance (MID), Spacing Metric (SM), and Diversification Metric (DM) and examined the performance of the proposed algorithm based on the SAW values derived from these three indicators. The calculated values for the boundaries obtained by the 


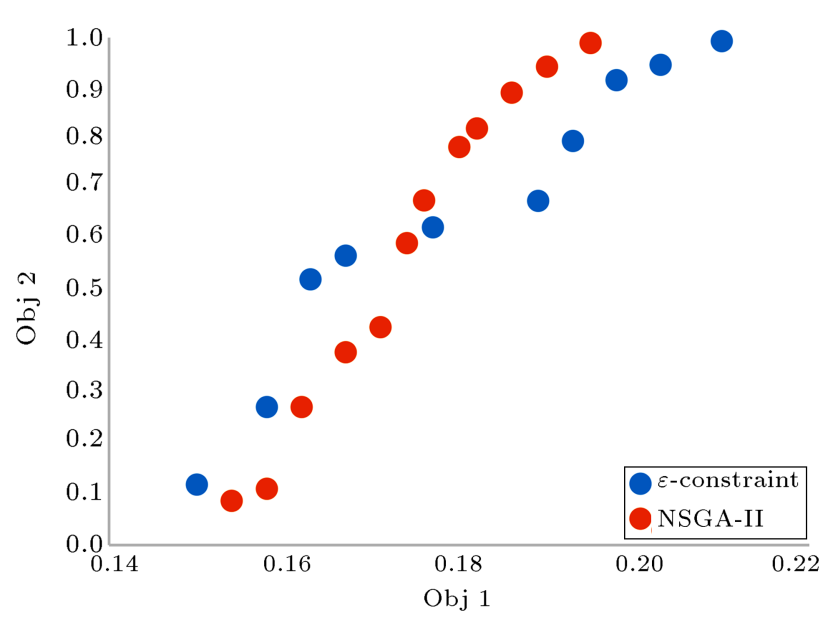

Figure 7. Pareto front in the third problem for the first and second objective functions.

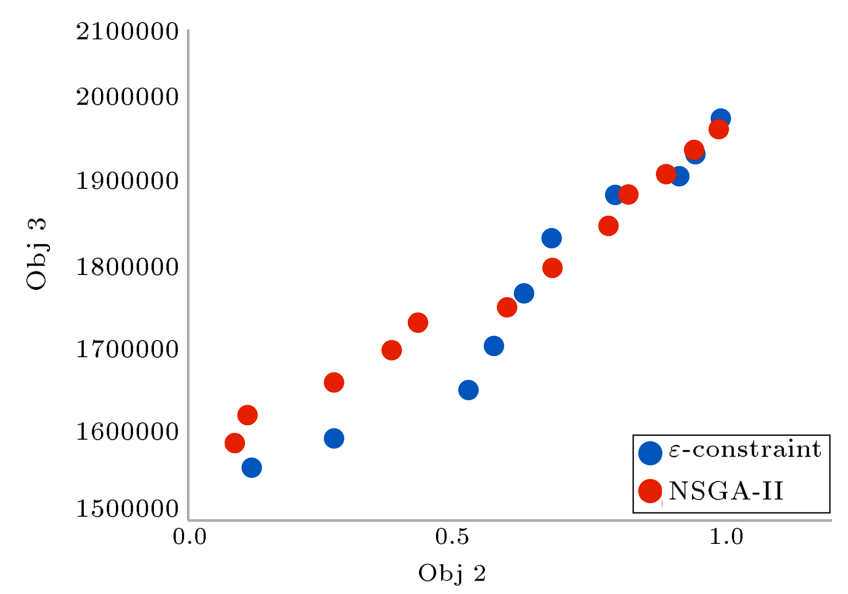

Figure 8. Pareto front in the third problem for the second and third objective functions.

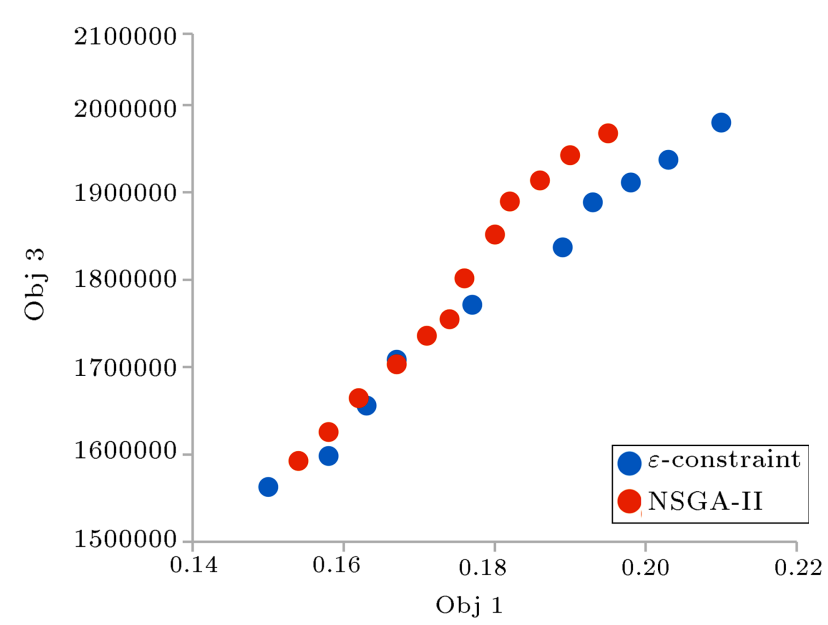

Figure 9. Pareto front in the third problem for the first and third objective functions.

two algorithms for the sample Problems 1 to 10 are given in Table 10.

According to Table 10, the NSGA-II works very close to the $\varepsilon$-constraint method. In this table, Prob-

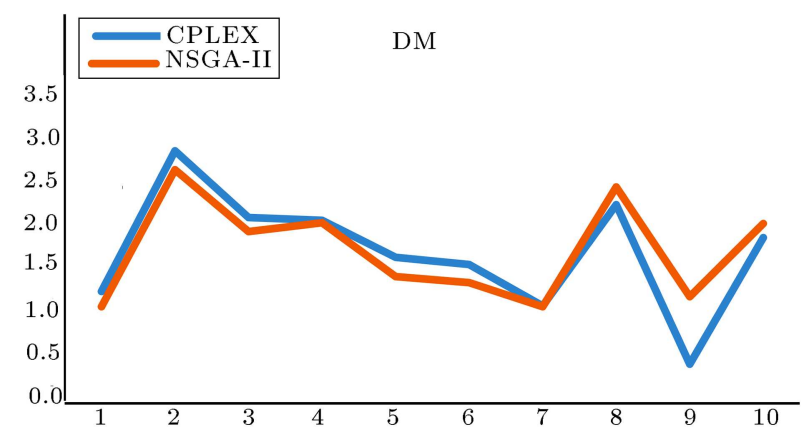

Figure 10. Comparison of Diversification Metric (DM) index for EC and NSGA-II methods.

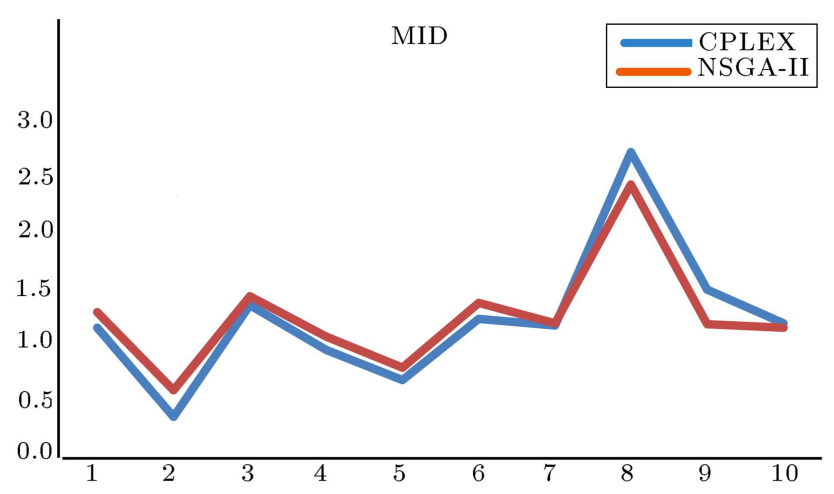

Figure 11. Comparison of Mean Ideal Distance (MID) index for EC and NSGA-II methods.

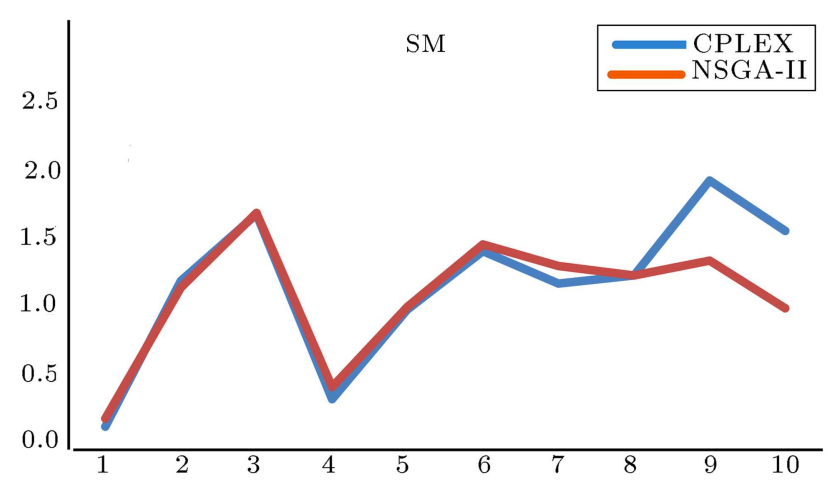

Figure 12. Comparison of the Spacing Metric (SM) index for both EC and NSGA-II methods.

lems 1 to 4 are small, Problems 5 to 7 are medium, and Problems 8 to 10 are big problems. Notably, from Problem 8 on, the $\varepsilon$-constraint algorithm was unable to solve the exact problem within the time limit of 3600 seconds and the best result was reported within this time period. As seen for the problems, the NSGA-II has relatively better indices. Figures 10 to 12 depict the comparison results for the three different metrics.

For the MID index, the $\varepsilon$-constraint method always shows better performance. This means that this algorithm produces more close solutions than the ideal point (in this research, the ideal point refers to the original coordinates). Regarding the SM index, almost 
Table 10. Validation of the $\varepsilon$-constraint method and NSGA-II.

\begin{tabular}{ccccccc}
\hline & \multicolumn{2}{c}{ DM } & \multicolumn{2}{c}{ MID } & \multicolumn{2}{c}{ SM } \\
\cline { 2 - 7 } Problem & EC & NSGA-II & EC & NSGA-II & EC & NSGA-II \\
\hline 1 & 1.29 & 1.11 & 1.11 & 1.31 & 0.17 & 0.23 \\
2 & 2.91 & 2.69 & 0.49 & 0.61 & 1.24 & 1.39 \\
3 & 2.14 & 1.98 & 1.01 & 1.45 & 1.73 & 1.74 \\
4 & 2.11 & 2.08 & 0.89 & 1.09 & 0.37 & 0.46 \\
5 & 1.68 & 1.46 & 1.75 & 1.91 & 1.03 & 1.05 \\
6 & 1.6 & 1.39 & 1.09 & 1.41 & 1.46 & 1.51 \\
7 & 1.12 & 1.11 & 1.15 & 1.21 & 1.22 & 1.35 \\
8 & 2.69 & 2.49 & 2.09 & 2.45 & 1.28 & 1.28 \\
9 & 0.45 & 1.23 & 1.23 & 1.2 & 1.98 & 1.39 \\
10 & 1.91 & 2.07 & 2.07 & 1.17 & 1.61 & 1.04 \\
\hline
\end{tabular}

Table 11. Computational times of EC and NSGA-II for solving 10 problems.

\begin{tabular}{cccccc}
\hline Computational time (s) & Problem 1 & Problem 2 & Problem 3 & Problem 4 & Problem 5 \\
\hline EC & 2.9 & 27.5 & 113.9 & 396.4 & 142 \\
NSGA-II & 9.6 & 26.8 & 83.1 & 804.8 & 221.3 \\
\hline Computational time (s) & Problem 6 & Problem 7 & Problem 8 & Problem 9 & Problem 10 \\
\hline EC & 1798.7 & 3312.6 & 3600 & 3600 & 3600 \\
NSGA-II & 274.5 & 296.7 & 542.3 & 882.4 & 965.7 \\
\hline
\end{tabular}

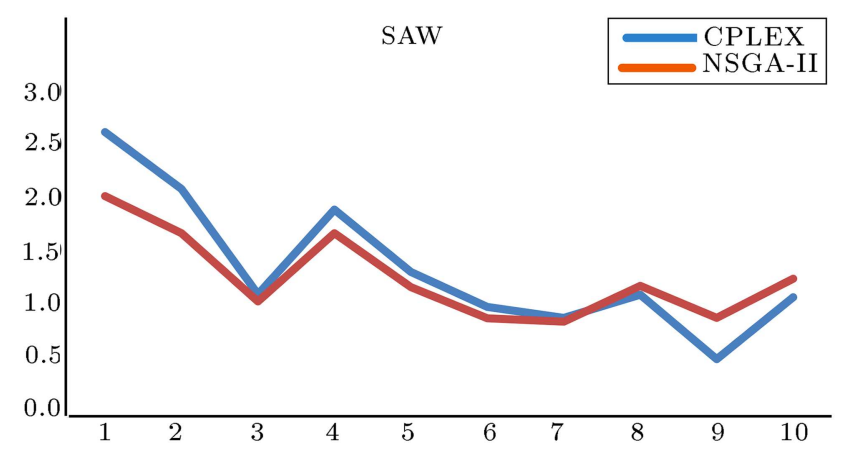

Figure 13. General comparison of EC and NSGA-II methods.

the same function is observed. However, by increasing the dimensions of the problem, the NSGA-II gradually reaches smaller distances between the produced Pareto solutions. In other words, with increasing dimensions of the problem, the NSGA-II succeeds in finding more Pareto optimal solutions, which would reduce the average distance between two successive Pareto solutions.

For the DM index, by increasing dimensions of the problem, the NSGA-II produces varied solutions. This means that the Pareto front generated by this algorithm covers a wider range of solutions.

Figure 13 gives a general comparison of the two approaches. As can be seen, the NSGA-II algorithm works well on large-scale problems. Therefore, the meta-heuristic algorithm used in this study is close to

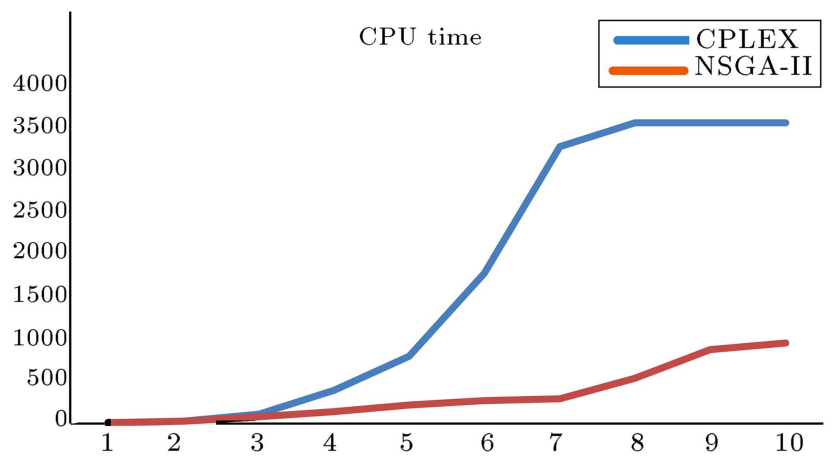

Figure 14. CPU times of EC and NSGA-II methods.

the exact solution and can, therefore, be a suitable tool for solving the problem when the exact solution is ineffective. As it is apparent, the SAW values of the NSGA-II are very close to the exact method. Moreover, the mean computational time is given in Table 11. According to this table, the computational time for the NSGA-II is much lower than that for the exact solution. Figure 14 depicts the comparison results of the computational time for these two approaches. Regarding the performance of the NSGA-II and its computational time, it can generally be considered a suitable tool for solving high-dimensional problems in a reasonable time and it may be expected to produce close-to-optimal or local solutions in much less time than to the exact method. 


\section{Case study}

After verifying the proposed model and evaluating the solution methods, we examined the performance of the proposed model by analyzing a case study as a disaster simulation problem. For this purpose, the Mazandaran province (including the cities of Amol and Babol) was selected as the candidate location vulnerable to earthquake events. Data related to the fault map of the Mazandaran province is illustrated in Figure 15 [52]. It should be noted that the data was acquired for the case study from the Crisis Management Organization of Mazandaran province, Red Crescent Society of Mazandaran Province, and Mazandaran Healthcare Network.

According to data of the active fault maps of Iran published by the International Institute of Seismology and Earthquake Engineering, several active faults are located in this province, including the Khazar and Northern Alborz faults. Therefore, considering the span of active faults and their density in the north of Iran, from the east to the west of the Mazandaran province, full prior preparedness and planning are necessary for dealing with possible events. Regarding the existence of the active Khazar fault and historical background of the earthquake, we consider two cities of Amol and Babol as vulnerable areas to possible earthquake occurrences. Three cities of Sari, Tehran, and Karaj are considered as supply centers that supply relief commodity. Sari supplies the goods from the road located in the non-mountainous area in the same province. Tehran and Karaj supply the aforementioned cities from the Haraz and Chalus mountainous roads, respectively, which are completely separate routes to Mazandaran province. Relief products in this example are tents, blankets, food packs, and hygiene packages. Food packages for four people include $10 \mathrm{~kg}$ of rice, 10 cans, 4 cans of vegetable oil, and 20 bottles of drinking water. Health packages for four people include 6 soaps, 2 cans of powdered laundry detergents, and 8 gallons of water. From the disaster management centers of Semnan, Alborz, and Tehran provinces, relief goods would be sent through three separate roads of Firooz Kooh, Chalus, and Haraz to the Mazandaran province. Thus, 4 cities of Sari, Karaj, Tehran, and Semnan were considered as candidates for disaster management centers, which had the initial inventory of some relief goods and could purchase other needed goods.
The hospitals intended for the problem included Shahid Beheshti, Ayatollah Rouhani, and Shahid Yahya Nejad hospitals in Babol and Imam Reza, 17 Shahrivar, and Imam Ali hospitals in Amol. Field hospitals of each city would be located nearest to the vulnerable point. In total, six hospitals and six field hospitals were used for medical services. An ambulance with a capacity of 4 people (2 people in 2 rounds) was used to move the injured from vulnerable areas to hospitals and field hospitals.

For prioritizing the displacement of injured people, various weights were considered according to the type of injury such that, for instance, the second type of injury was considered worse with higher weight (0.65) than the first type of injury (0.35) for its displacement rate. The cost of goods shortage in the affected areas was constant and equal to 0.35 . The minimum percentage of relief goods in the affected area, $\omega$, was equal to 0.15 .

After the uncertainty space was applied as a robust optimization case study problem, the parameters were $\Gamma_{0}^{\prime}=1, \Gamma_{0}^{\prime \prime}=1, \Gamma 1_{i z}=0.2$, and $\Gamma 2_{k z}=0.4$. The uncertainty level for all parameters was considered to be 0.25 and the computational results obtained from the NSGA-II were examined as Pareto front development. According to the experts' opinion, the best point on this boundary was chosen and values were achieved for the objectives, as given in Table 12 .

As can be found from the output of the case study problem solution, the amount of Objective 1 was more than that of Objective 2, which means increasing the justice of serving the injured people versus the justice of managing the commodity crisis. On the other hand, the total cost was estimated at 15.5 billion Rials $(\approx 155000$ US $\$$ ). The graphical output of the proposed model is presented in Figure 16. A total of six existing hospitals and six candidate field hospitals were used for health services. The total number of launched disaster management centers was equal to two units of large and medium sizes in Sari and Tehran (out of four candidate centers), the number of field hospitals was equal to three units from six candidate centers, and the number of distribution centers that were set up in the model was equal to two units out of four candidates. The output of the proposed model algorithm can be an important tool for organizations related to crisis management to estimate the necessary facilities and improve the crisis services. It can depict under different scenarios the output required to cope

Table 12. Output of the case study problem.

\begin{tabular}{cccccc}
\hline Objective 1 & Objective 2 & Objective 3 & $\begin{array}{c}\text { No. of } \\
\text { erected disaster } \\
\text { centers }\end{array}$ & $\begin{array}{c}\text { No. of } \\
\text { erected field } \\
\text { hospitals }\end{array}$ & $\begin{array}{c}\text { No. of } \\
\text { erected distribution } \\
\text { centers }\end{array}$ \\
\hline 0.89 & 0.67 & 15534892560 & 2 & 3 & 2 \\
\hline
\end{tabular}


(a)

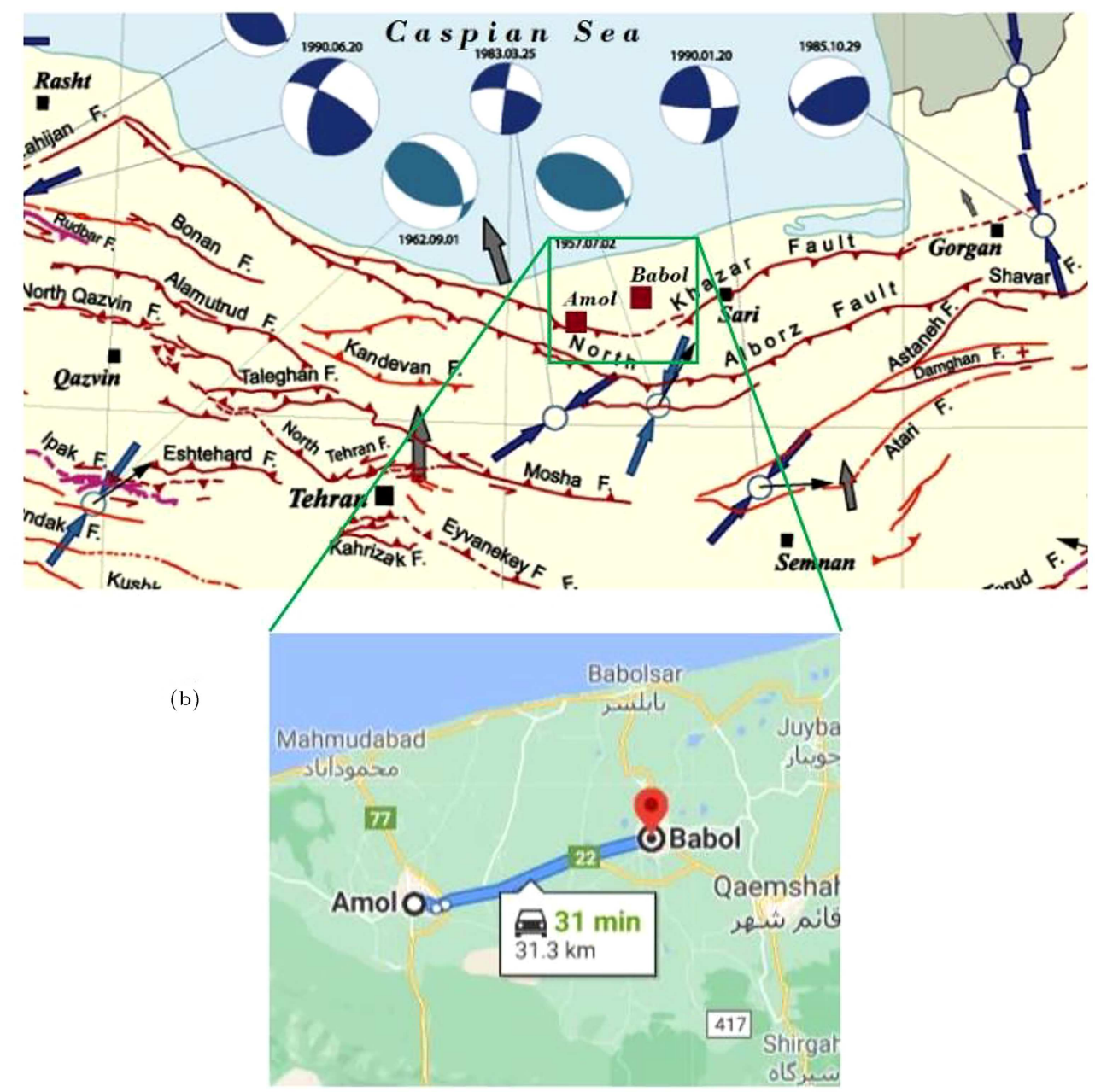

Legend

Fault classification

\begin{tabular}{|c|c|c|c|c|}
\hline Type of active fault & \multicolumn{2}{|c|}{$\begin{array}{l}\text { Fault machanism and } \\
\text { notation }\end{array}$} & \multicolumn{2}{|r|}{ Seismological legend } \\
\hline $\begin{array}{l}\text { Earthquake fault (surface } \\
\text { rupture associated with } \\
\text { earthquake) }\end{array}$ & $\hookrightarrow$ & $\begin{array}{l}\text { Thrust and reverse } \\
\text { faults }\end{array}$ & 0 & Earthquake location \\
\hline $\begin{array}{l}\text { Seismically active fault (fault } \\
\text { whose seismic activity has } \\
\text { documented but not resulted } \\
\text { in surface repture) }\end{array}$ & & $\begin{array}{l}\text { Fault without } \\
\text { specification } \\
\text { strike slip fault } \\
\text { with sense of } \\
\text { motion }\end{array}$ & $\bullet$ & $\begin{array}{l}\text { Focal mechanism solutions } \\
\text { of earthquakes occurring in } \\
\text { the interval 1948-1976 }\end{array}$ \\
\hline \multirow[t]{3}{*}{$\begin{array}{l}\text { Documented quaternary } \\
\text { fault (fault which has been } \\
\text { active during the quaternary } \\
\text { times) }\end{array}$} & \pm & $\begin{array}{l}\text { Relative upthrown } \\
\text { and downthrown } \\
\text { sides }\end{array}$ & \multirow[b]{2}{*}{$\longrightarrow$} & $\begin{array}{l}\text { Focal mechanism solutions } \\
\text { of earthquakes occurring in } \\
\text { the interval 1976-2002 }\end{array}$ \\
\hline & \multirow{2}{*}{\multicolumn{2}{|c|}{$\begin{array}{ll}\text { Inferred fault } \\
\text { location }\end{array}$}} & & $\begin{array}{l}\text { Horizontal component of slip } \\
\text { vector }\end{array}$ \\
\hline & & & \multicolumn{2}{|c|}{ 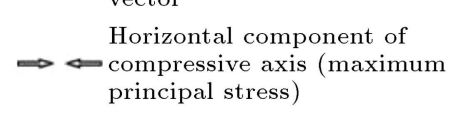 } \\
\hline \multicolumn{5}{|c|}{$\begin{array}{c}\text { Special notation } \\
\text { GPS velocities in eurasia-fixed refrence } \\
\text { frame, } 1 \mathrm{~cm} / \text { year }\end{array}$} \\
\hline Scale $1: 2,500,000$ & 0 & 100 & 150 & $200 \mathrm{~km}$ \\
\hline
\end{tabular}

Figure 15. (a) Map of the fault zone in the Mazandaran province including the cities of Babol and Amol (adapted from Hessami et al. [52]) and (b) satellite image of the study area. 


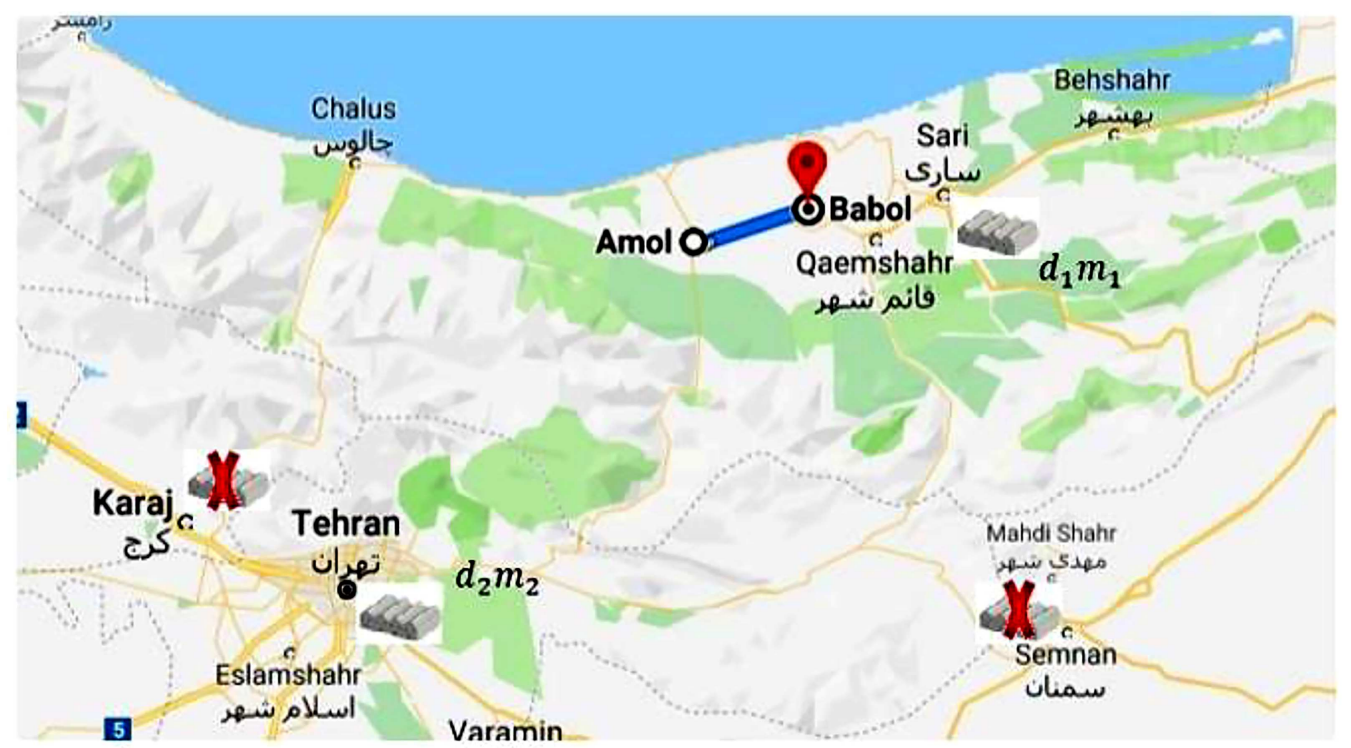

(a)

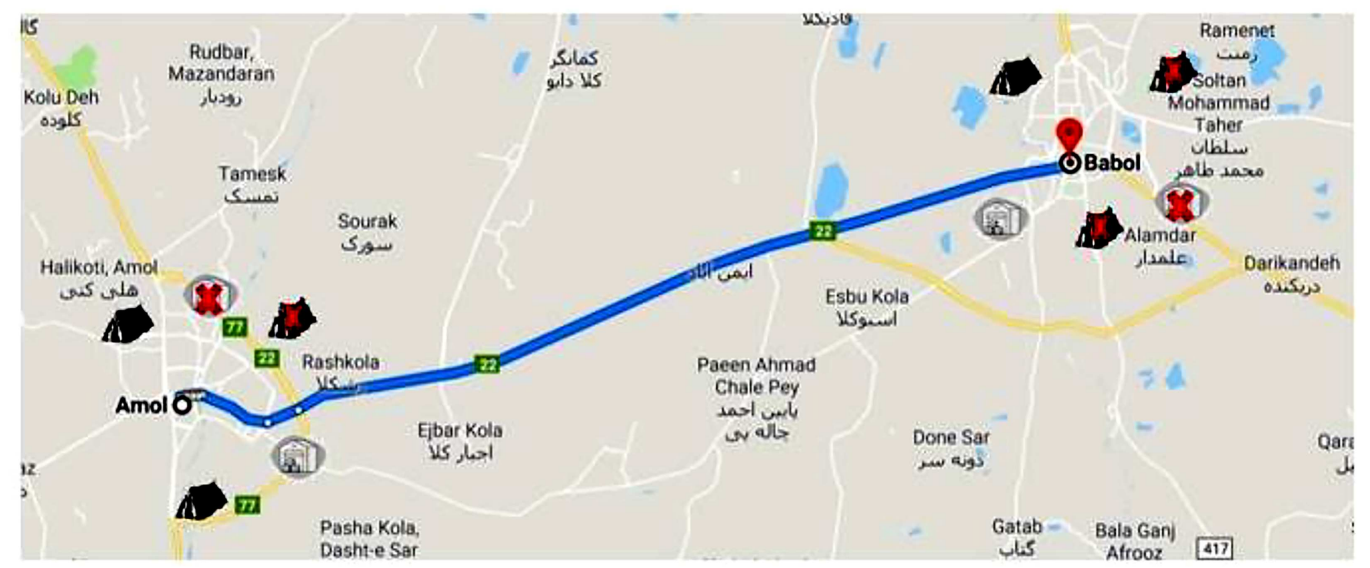

(b)

Figure 16. Graphical output: (a) Erected disaster management sites and (b) erected emergency tents and distribution centers.

Table 13. Changes in objectives by different amounts of $I N I_{d k}$.

\begin{tabular}{cccccc}
\hline & $\mathbf{0 . 5} \boldsymbol{I N} \boldsymbol{I}_{\boldsymbol{d} \boldsymbol{k}}$ & $\mathbf{0 . 7 5} \boldsymbol{I} \boldsymbol{N} \boldsymbol{I}_{\boldsymbol{d} \boldsymbol{k}}$ & $\boldsymbol{I N} \boldsymbol{I}_{\boldsymbol{d} \boldsymbol{k}}$ & $\mathbf{1 . 2 5} \boldsymbol{I} \boldsymbol{N} \boldsymbol{I}_{\boldsymbol{d} \boldsymbol{k}}$ & $\mathbf{1 . 5} \boldsymbol{I N} \boldsymbol{I}_{\boldsymbol{d} \boldsymbol{k}}$ \\
\hline Objective 1 & 0.89 & 0.89 & 0.89 & 0.89 & 0.89 \\
Objective 2 & 0.43 & 0.59 & 0.67 & 0.76 & 0.88 \\
Objective 3 & 1672134755 & 15908207144 & 15534892560 & 15107328955 & 14478201388 \\
\hline
\end{tabular}

with simulated crises regarding the decrease or increase in actual opportunities available in the area.

Moreover, by implementing the case study, some managerial insights can be given as follows, which are useful for managers and decision-makers in disasters.

- Keeping a reasonable quantity of initial commodity inventory is a vital necessity for disasters. The greater the inventory, the more supply can be done during a disaster to increase fairness in the commodity distribution and reduce the costs. The problem was solved for different values of initial commodity inventory in the present paper and the results showed that by maintaining an appropriate level of initial inventory, the fairness of commodity distribution increased and the cost decreased (Table 13 ).

- Encouraging people to donate goods is highly important. A high amount of goods donation results in a higher rate of commodity fairness and cost reduction. Thus, having a plan for the attraction 
Table 14. Changes in objectives by different amounts of $P D_{d k}$.

\begin{tabular}{lccccc}
\hline & $\mathbf{0 . 5} \boldsymbol{P} \boldsymbol{D}_{\boldsymbol{d} \boldsymbol{k}}$ & $\mathbf{0 . 7 5} \boldsymbol{P} \boldsymbol{D}_{\boldsymbol{d k}}$ & $\boldsymbol{P D}_{\boldsymbol{d k}}$ & $\mathbf{1 . 2 5} \boldsymbol{P} \boldsymbol{D}_{\boldsymbol{d k}}$ & $\mathbf{1 . 5} \boldsymbol{P} \boldsymbol{D}_{\boldsymbol{d k}}$ \\
\hline Objective 1 & 0.89 & 0.89 & 0.89 & 0.89 & 0.89 \\
Objective 2 & 0.59 & 0.63 & 0.67 & 0.71 & 0.71 \\
Objective 3 & 169127228337 & 16273650891 & 15534892560 & 14784245881 & 14784245881 \\
\hline
\end{tabular}

of people to donate goods is greatly recommended. For instance, different amounts of goods donation have been surveyed in Table 14. However, note that, after a certain level of donation, there would be no increase or decrease in the objective (e.g., from 1.25 PDdk to 1.5 PDdk). In other words, blood donation should increase up to a certain level.

- The changes in the amount of donation have a greater effect on the objective than the fluctuation of the initial inventory. Notwithstanding, according to Tables 13 and 14, fluctuations in the amount of donation result in changes in commodity fairness and costs. In summary, in identical amounts of changes, donation plays the most important role in fairness and cost reduction.

\section{Conclusion and further recommendations}

In this research, a multi-objective, multi-commodity, multi-vehicle, and multi-level logistic problem was presented in a disastrous situation under uncertainty. To deal with the uncertainty, a robust mixed-integer nonlinear programming mathematical model was presented. In addition to the robustness of parameters (e.g., the number of affected people and the number of needed goods), other specific features of the problem such as the diversity of injuries and public assistance besides implementing a case study in Mazandaran were the major contributions of this study.

The model was aimed to maximize the fair servicing for the injured people, maximize the fairness of commodity distribution, and minimize the total cost of the network. To solve the problem, a Nondominated Sorting Genetic Algorithm-II (NSGA-II) was developed and its parameters were tuned using the Taguchi method. Also, to achieve high quality results, a heuristic algorithm was developed to generate the initial solutions. Three measures including Diversification Metric (DM), Spacing Metric (SM), and Mean Ideal Distance (MID) were used to validate and evaluate the proposed NSGA-II. The NSGA-II could generally be considered a suitable tool for solving high-dimensional problems in a reasonable time and it might be expected to produce close-to-optimal or local solutions in much less time than to the exact method.

To confirm the relevance of the subject and applicability of the provided tools, a case study analysis was carried out for an area of condensed active faults with historic earthquake records in the north of Iran. The analysis proved the efficiency of the approach. The results indicated that keeping a reasonable quantity of initial commodity inventory was a vital necessity for disasters. By maintaining a higher level of inventory, more supply could be done and shortage was prohibited. Therefore, having plans for encouraging people to donate, especially blood, seems highly important. This leads to a higher rate of commodity fairness and cost reduction. Moreover, objectives showed higher sensitivity to the changes in donation than to the initial inventory. This proves that donation plays the most important role in fairness and cost reduction in disasters.

To develop the work in the future, it is suggested to use different modes of transportation, such as aerial transportation, which is very helpful in a disastrous situation. Moreover, considering the routing decisions at the operational level with route failure in disasters can add more value to the research. Likewise, considering the failure of relief distribution centers or disaster management centers caused by possible disasters would be interesting for future research.

\section{References}

1. Mohamadi, A. and Yaghoubi, S. "A bi-objective stochastic model for emergency medical services network design with backup services for disasters under disruptions: An earthquake case study", International Journal of Disaster Risk Reduction, 23, pp. 204-217 (2017).

2. Najafi, M., Eshghi, K., and Dullaert, W. "A multiobjective robust optimization model for logistics planning in the earthquake response phase", Transportation Research Part E: Logistics and Transportation Review, 49, pp. 217-249 (2013).

3. Balcik, B. and Beamon, B.M. "Facility location in humanitarian relief", International Journal of Logistics, 11(2), pp. 101-121 (2008).

4. Qureshi, A.G. and Taniguchi, E. "A multi-period humanitarian logistics model considering limited resources and network availability", Transportation Research Procedia, 46, pp. 212-219 (2020).

5. Gökçe, M.A. and Ercan, E. "Multi-period vehicle routing \& replenishment problem of neighbourhood disaster stations for pre-disaster humanitarian relief 
logistics", IFAC-Papers OnLine, 52(13), pp. 2614-2619 (2019).

6. Lindell, M.K. "Disaster studies", Current Sociology Review, 61, pp. 797-825 (2013).

7. Berke, P.R. "Natural-hazard reduction and sustainable development: A global assessment", Journal of Planning Literature, 9, pp. 370-382 (1995).

8. Mastane, Z., Moseli, L., and Jahangir, M. "Capabilities and limitations of crisis management in hospitals", Fasa Journal University of Medical Sciences, 41, pp. 244-250 (2013).

9. Mohamadi, A., Yaghoubi, S., and Pishvaee, M.S. "Fuzzy multi-objective stochastic programming model for disaster relief logistics considering telecommunication infrastructures: a case study", Operational Research, 19(1), pp. 59-99 (2019).

10. Bertsimas, D. and Sim, M. "The price of robustness", Operations Research, 52(1), pp. 35-53 (2004).

11. Toregas, C., Swain, R., ReVelle, C., et al. "The location of emergency service facilities", Operations Research, 19(6), pp. 1363-1373 (1971).

12. Knott, R.P. "Vehicle scheduling for emergency relief management: A knowledge-based approach", Disasters, 12(4), pp. 285-293 (1988).

13. Haghani, A. and Oh, S.C. "Formulation and solution of a multi-commodity, multi-modal network flow model for disaster relief operations", Transportation Research Part A: Policy and Practice, 30(3), pp. 231-250 (1996).

14. Barbarosoğlu, G., Özdamar, L., and Cevik, A. "An interactive approach for hierarchical analysis of helicopter logistics in disaster relief operations", European Journal of Operational Research, 140, pp. 118-133 (2002).

15. Özdamar, L., Ekinci, E. and Küçükyazici, B. "Emergency logistics planning in natural disasters", Annals of Operations Research, 129, pp. 217-245 (2004).

16. Tzeng, G.H., Cheng, H.J., and Huang, T.D. "Multiobjective optimal planning for designing relief delivery systems", Transportation Research Part E: Logistics and Transportation Review, 43(6), pp. 673-686 (2007).

17. Sheu, J.B. "Dynamic relief-demand management for emergency logistics operations under large-scale disasters", Transportation Research Part E: Logistics and Transportation Review, 46(1), pp. 1-17 (2010).

18. Afshar, A. and Haghani, A. "Modeling integrated supply chain logistics in real-time large-scale disaster relief operations", Socio-Economic Planning Sciences, 46(4), pp. 327-338 (2012).

19. Camacho-Vallejo, J.F., González-Rodríguez, E., Almaguer, F.J., et al. "A bi-level optimization model for aid distribution after the occurrence of a disaster", Journal of Cleaner Production, 105, pp. 134-145 (2015).

20. Boonmee, C., Arimura, M., and Asada, T. "Facility location optimization model for emergency humanitarian logistics", International Journal of Disaster Risk Reduction, 24, pp. 485-498 (2017).
21. Rodríguez-Espíndola, O., Albores, P., and Brewster, C. "Disaster preparedness in humanitarian logistics: A collaborative approach for resource management in floods", European Journal of Operational Research, 264(3), pp. 978-993 (2018).

22. Barbarosoğlu, G. and Arda, Y. "A two-stage stochastic programming framework for transportation planning in disaster response", Journal of the Operational Research Society, 55(1), pp. 43-53 (2004).

23. Yi, W. and Özdamar, L. "A dynamic logistics coordination model for evacuation and support in disaster response activities", European Journal of Operational Research, 179(3), pp. 1177-1193 (2007).

24. Bozorgi-Amiri, A., Jabalameli, M.S., and Mirzapour Al-e-Hashem, S.M. "A multi-objective robust stochastic programming model for disaster relief logistics under uncertainty", OR Spectrum, 35(4), pp. 905-933 (2013).

25. Mohamadi, A., Yaghoubi, S., and Derikvand, H. "A credibility-based chance-constrained transfer point location model for the relief logistics design (Case study: earthquake disaster on region 1 of Tehran city)", International Journal of Supply and Operations Management, 1(4), pp. 466-488 (2015).

26. Chen, A.Y. and Yu, T.Y. "Network based temporary facility location for the Emergency Medical Services considering the disaster induced demand and the transportation infrastructure in disaster response", Transportation Research Part B: Methodological, 91, pp. 408-423 (2016).

27. Manopiniwes, W. and Irohara, T. "Stochastic optimisation model for integrated decisions on relief supply chains: preparedness for disaster response", International Journal of Production Research, 55(4), pp. 979-996 (2017).

28. Rabbani, M., Zhalechian, M., and FarshbafGeranmayeh, A. "A robust possibilistic programming approach to multiperiod hospital evacuation planning problem under uncertainty", International Transactions in Operational Research, 25(1), pp. 157-189 (2018).

29. Vahdani, B., Veysmoradi, D., Noori, F., et al. "Twostage multi-objective location-routing-inventory model for humanitarian logistics network design under uncertainty", International Journal of Disaster Risk Reduction, 27, pp. 290-306 (2018).

30. Zanganeh, M., Ebrahimnejad, S., Moosavi, A., et al. "A bi-objective model for humanitarian logistics network design in response to post-disaster", International Journal of Logistics Systems and Management, 33(2), pp. 256-279 (2019).

31. Samani, M.R.G., Torabi, S.A., and Hosseini-Motlagh, S.M. "Integrated blood supply chain planning for disaster relief", International Journal of Disaster Risk Reduction, 27, pp. 168-188 (2018). 
32. Elluru, S., Gupta, H., Kaur, H., et al. "Proactive and reactive models for disaster resilient supply chain", Annals of Operations Research, 283(1-2), pp. 199-224 (2019).

33. Zhang, J., Wang, Z., and Ren, F. "Optimization of humanitarian relief supply chain reliability: a case study of the Ya'an earthquake", Annals of Operations Research, 283(1), pp. 1551-1572 (2019).

34. Shavarani, S.M. "Multi-level facility locationallocation problem for post-disaster humanitarian relief distribution", Journal of Humanitarian Logistics and Supply Chain Management, 9(1), pp. 70-81 (2019).

35. Salehi, F., Mahootchi, M., and Husseini, S.M.M. "Developing a robust stochastic model for designing a blood supply chain network in a crisis: A possible earthquake in Tehran", Annals of Operations Research, 283(1-2), pp. 679-703 (2019).

36. Samani, M.R.G. and Hosseini-Motlagh, S.M. "An enhanced procedure for managing blood supply chain under disruptions and uncertainties", Annals of Operations Research, 283(1), pp. 1413-1462 (2019).

37. Tirkolaee, E.B., Hadian, S., Weber, G.W., et al. "A robust green traffic-based routing problem for perishable products distribution", Computational Intelligence, 36(1), pp. 80-101 (2020).

38. Nabipoor Afruzi, E., Aghaie, A., and Najafi, A.A. "Robust optimization for the resource-constrained multiproject scheduling problem with uncertain activity durations", Scientia Iranica, 27(1), pp. 361-376 (2020).

39. Golpǐra, H. and Tirkolaee, E.B. "Stable maintenance tasks scheduling: A bi-objective robust optimization model", Computers \& Industrial Engineering, 137, p. 106007 (2019).

40. Sangaiah, A.K., Tirkolaee, E.B., Goli, A., et al. "Robust optimization and mixed-integer linear programming model for LNG supply chain planning problem", Soft Computing, 24, pp. 7885-7905 (2020).

41. Tirkolaee, E.B., Mahdavi, I., Esfahani, M.M.S., et al. "A robust green location-allocation-inventory problem to design an urban waste management system under uncertainty", Waste Management, 102, pp. 340-350 (2020).

42. Adarang, H., Bozorgi-Amiri, A., Khalili-Damghani, K., et al. "A robust bi-objective location-routing model for providing emergency medical services", Journal of Humanitarian Logistics and Supply Chain Management, 10(3), pp. 285-319 (2020).

43. Samani, M.R.G., Hosseini-Motlagh, S.M., and Ghannadpour, S.F. "A multilateral perspective towards blood network design in an uncertain environment: Methodology and implementation", Computers \& Industrial Engineering, 130, pp. 450-471 (2019).

44. Erbeyoğlu, G. and Bilge, Ü. "A robust disaster preparedness model for effective and fair disaster re- sponse", European Journal of Operational Research, 280(2), pp. 479-494 (2020).

45. Haeri, A., Hosseini-Motlagh, S.M., Ghatreh Samani, M.R., et al. "A mixed resilient-efficient approach toward blood supply chain network design", International Transactions in Operational Research, 27(4), pp. 1962-2001 (2020).

46. Aghezzaf, E.H., Sitompul, C., and Najid, N.M. "Models for robust tactical planning in multi-stage production systems with uncertain demands", Computers \& Operations Research, 37(5), pp. 880-889 (2010).

47. Ahmadi, G., Tavakkoli-Moghaddam, R., Baboli, A., et al. "A decision support model for robust allocation and routing of search and rescue resources after earthquake: A case study", Operational Research: An International Journal, 22(2), pp. 1039-1081 (2022).

48. Bérubé, J.F., Gendreau, M., and Potvin, J.Y. "An exact $\epsilon$-constraint method for bi-objective combinatorial optimization problems: Application to the traveling salesman problem with profits", European Journal of Operational Research, 194(1), pp. 39-50 (2009).

49. Deb, K., Pratap, A., Agarwal, S., et al. "A fast and elitist multiobjective genetic algorithm: NSGAII", IEEE Transactions on Evolutionary Computation, 6(2), pp. 182-197 (2002).

50. Ullrich, C.A. "Integrated machine scheduling and vehicle routing with time windows", European Journal of Operational Research, 227(1), pp. 152-165 (2013).

51. Taguchi, G., Chowdhury, S., and Wu, Y., Taguchi's Quality Engineering Handbook, 1736, Hoboken, NJ: John Wiley \& Sons (2005).

52. Hessami, K., Jamali, F., and Abasi, H. "Major active faults of Iran", International Institute of Earthquake Engineering and Seismology (IIEES), Tehran, Iran (2003).

\section{Biographies}

Ali Akbar Eshghi is a PhD student of Industrial Engineering at Islamic Azad University, South Tehran Branch, in Iran. He received his BSc and MSc degrees in Industrial Engineering from Iran University of Science \& Technology and Mazandaran University of Science and Technology in 2005 and 2011, respectively. His research interest areas include Locationallocation planning, multi-objective evolutionary algorithm, disaster management, and optimization under uncertainty. He has published a number of papers in journals and conferences.

Reza Tavakkoli-Moghaddam is a Professor of Industrial Engineering at the College of Engineering, University of Tehran, in Iran. He obtained his PhD, $\mathrm{MSc}$, and BSc degrees in Industrial Engineering from Swinburne University of Technology in Melbourne in 1998, University of Melbourne in 1994, and Iran University of Science and Technology in 1989, respectively. 
He serves as the Editor-in-Chief of the Journal of Industrial Engineering published by the University of Tehran and the Editorial Board member of nine reputable academic journals. He is the recipient of the 2009 and 2011 Distinguished Researcher Awards and the 2010 and 2014 Distinguished Applied Research Awards at University of Tehran, Iran. He has been selected as the National Iranian Distinguished Researcher in 2008 and 2010 by the MSRT (Ministry of Science, Research, and Technology) in Iran. He has been among the top $1 \%$ scientist and researchers in the world elite group. He has published 5 books, 30 book chapters, and more than 1000 journal and conference papers.

Sadoullah Ebrahimnejad is an Associate Professor of Industrial Engineering at Islamic Azad University, Karaj Branch, in Iran. He received his BSc degree from Iran University of Science \& Technology in 1986, MSc degree from Amirkabir University of Technology in 1993, and PhD degree from Islamic Azad University,
Science \& Research Branch, in Tehran in 2001. His research interests are fuzzy MADM/MODM, SCM, operations management, optimization models, risk management, and multi-criteria network optimization. He has published more than 90 papers in reputable academic journals and conferences.

Vahid Reza Ghezavati is currently Associate Professor at the Industrial Engineering College of South Tehran Branch of Islamic Azad University. He received his BSc degree in 2005, MSc in 2007, and PhD in 2010 all in Industrial Engineering from the Iran University of Science \& Technology. His research interests include supply chain, decision making techniques, manufacturing systems, queuing theory, and mathematical modeling. He has authored papers published in several journals, including Engineering Optimization, ASOC, JCLP, SOCO, CAIE, ESWA, CAM, Journal of Engineering Manufacture: Part B, Simulation, Kybernetes, IJAMT, CJOR, ECECSR, and some other journals and conference proceedings. 